Version of Record: https:/www.sciencedirect.com/science/article/pii/S0010938X18314975

Manuscript_1385a09eceb0e6465ce987eca3ea9d7e

\title{
On the intrinsic passivating ability of Belite-Ye'elimite-Ferrite towards carbon steel: a straightforward comparison with ordinary Portland cement
}

Guilherme Yuuki Koga ${ }^{\mathrm{a}, \mathrm{b}, *}$, Blandine Albert ${ }^{\mathrm{a}}$, Virginie Roche ${ }^{\mathrm{b}}$, Ricardo Pereira Nogueira ${ }^{\mathrm{b}, \mathrm{c}, *}$

${ }^{a}$ LafargeHolcim Research Center, 95, 38290, Saint Quentin Fallavier, France

${ }^{b}$ Grenoble Alpes University, CNRS, LEPMI, F-38000 Grenoble, France

${ }^{c}$ Gas Research Center, Khalifa University of Science and Technology, Abu Dhabi, UAE

Corresponding authors: ricardo.nogueira@ku.ac.ae, guilherme.koga@ dema.ufscar.br

\begin{abstract}
The quest for low-CO $\mathrm{O}_{2}$ emission alternatives to Portland cement is pushing the cement industry to develop new types of binders. Besides the need of equivalent mechanical properties, a major issue concerns the passivating ability of these new materials. BeliteYe'elimite-Ferrite binders $(B Y F)$ are attracting increasing interest of cement developers, but there are still doubts about their intrinsic protectiveness. Carbon steel passivation in BYF leachates was studied and compared to OPC leachates through electrochemical techniques and X-ray photoelectron spectroscopy. In both media, steel was highly passivated in less than 24 hours, protected by a ca 5 nm thickness film.
\end{abstract}

Keywords: Steel; Passivity; Sulfoaluminate cement; Portland cement; EIS; XPS. 


\section{Introduction}

Belite-Ye'elimite-Ferrite (BYF) cement family has been proposed as a lower-carbon alternative to the highly polluting ordinary Portland cement (OPC) [1]. Large fraction of the cement production is used to make concrete, which requires reinforcements in applications such as bridges, tunnels, sewer systems, dams, etc. To date, reinforced concrete based on OPC cement are the most used structural material in buildings and infrastructures worldwide. If BYF cements are intended for wide reinforced concrete use while remaining economically competitive, it is mandatory for BYF pore solutions to induce spontaneous passivation of inexpensive carbon steel rebars as the OPC pore solution does.

Pore solution chemistry of cementitious matrices is crucial for the understanding of the corrosion phenomena of steel in concrete. This solution is in equilibrium with the solid phases resulting from the cement hydration process, therefore, its composition is strongly dependent on the cement type. Studies have shown that the composition of the concrete pore solution affects the time to passivation [2], how passive film is formed [3], and its protectiveness against corrosion $[4,5]$. This means that realistic results for the behavior of steel in concrete are straightforwardly dependent on the testing solution to be effectively representative of the concrete pore solution.

To date, few results have been reported with respect to carbon steel passivation in electrolytes representative of BYF pore solution. Electrochemical studies on reinforcing steel bars in aqueous media have being traditionally conducted in synthetic electrolytes saturated with calcium hydroxide, $\mathrm{Ca}(\mathrm{OH})_{2}[6-11]$, with addition of ions such as $\mathrm{Na}^{+}, \mathrm{K}^{+},\left(\mathrm{SO}_{4}\right)^{2-}, \mathrm{Al}^{3+}$, $\mathrm{Si}^{2+}$, and $\mathrm{Fe}^{2+}$ that, in a lower or higher level, contribute to the complex interactions between the metallic surface and the cement's liquid phase. However, BYF systems are not saturated with calcium hydroxide but with ettringite, $\mathrm{Ca}_{6} \mathrm{Al}_{2}\left(\mathrm{SO}_{4}\right)_{3}(\mathrm{OH})_{12} \cdot 26 \mathrm{H}_{2} \mathrm{O}$ [12], which makes the 
current approach of using saturated calcium hydroxide solutions no longer representative. In addition, there is no synthetic model solution for hydrated BYF cement matrices.

Because BYF cements have a different composition than OPC ones and due to the novelty of the BYF binders [13], a consistent literature on the passivation of carbon steel in BYF pore solution is still missing. It is, however, worth citing the Janotka's et al. work [14], which indicated that, due to their low $\mathrm{pH}$, carbon steel should not passivate in BYF cement extracts. Similarly, Kalogridis et al. [15], using reinforced mortars, concluded that the low pH and the higher average pores of BYF matrix compared to OPC equivalent exposed the reinforcing steel to a higher corrosion risk. Those results are in line with the Koga's et al. work [16], which proposed that, unlikely to the OPC matrices pore solution that is highly passivating since the first minutes, the pore solution of BYF matrices should be less protective and could even be corrosive at early-age of hydration. However, as the hydration progresses, the pore solution of BYF matrices could become as protective as the OPC pore solution but the passivation in these conditions has not been thoroughly evaluated.

The objective of this study was to evaluate the passivation of carbon steel in BYF compared to OPC mature solutions, i.e., obtained from cement pastes cured for 28 days, a curing period generally used to characterize the concrete characteristics and properties. It is worth noticing that, to unambiguously assess the intrinsic passivating ability of BYF binders, this study has been carried out in the absence of aggressive agents as chlorides or carbon dioxide. Indeed, as mentioned before, there is a lack of knowledge about the interaction between BYF pore solutions and carbon steel so that their inherent protectiveness is still matter of doubt. This paper aimed to go deeper into this issue by evaluating the intrinsic passivating ability of BYF binders - once the effective protectiveness of BYF is unambiguously established, the effect of aggressive agents will be matter of a specific separate paper. Electrochemical measurements such as open-circuit potential (OCP) surveys, 
linear polarization resistance (LPR), and electrochemical impedance spectroscopy (EIS) were performed over 7 days to track the corrosion/passivation behavior of carbon steel. X-ray photoelectron spectroscopy (XPS) was performed as a complement, focusing on the characterization of the passive films at their first stages of formation, which were assimilated to corrosion current density values dropping to values below $0.1 \mu \mathrm{A} . \mathrm{cm}^{-2}$. Results were discussed in terms of the straightforward comparison between the protectiveness of 28-day cured OPC and BYF matrices leachate regarding steel passivation.

\section{Materials and Methods}

\subsection{Tested solutions}

Realistic concrete pore solution can, in principle, be obtained by pressing bulk specimens of concrete, mortar or cement paste against a steel die (steel die method [17]), resulting in small volume of aqueous phase for aged samples. However, electrochemical and surface analyses often require significant amount of electrolyte (hundreds of millimeters) so the use of the steel die method is not practical, especially for BYF matrices because of the high-water consumption during the hydration of ye'elimite, $\mathrm{Ca}_{4} \mathrm{Al}_{6} \mathrm{O}_{12}\left(\mathrm{SO}_{4}\right)$. To replicate the complexity of the electrolyte occurring in concrete, ex-situ leaching (ESL) procedure was used to obtain aqueous solutions from OPC and BYF cement pastes. Even if some dilution effect may occur during the ESL procedure, the resulting electrolytes (the leachates) are a reasonable approximation of the actual BYF pore solution inasmuch as no synthetic pore solution for this system has been proposed.

For the ESL procedure, the different pastes produced with a water to cement ratio (w/c) of 0.5 cured for 28 days were coarsely crushed $(<5 \mathrm{~mm})$, placed in HDPE bottles, and mixed with distilled water in a 1:1 mass ratio. The mineralogy and the density of the BYF and OPC cements are detailed in Table 1, and the phase assemblage of the OPC and BYF cement paste at 28 days shown in Figure 1. Leaching was sustained during $24 \mathrm{~h}$ under agitation, and $18 \mathrm{~h}$ 
of rest for decantation, being the solution double filtered to remove particulates using a $<45$ $\mu \mathrm{m}$ Millipore membrane filter and a mechanical vacuum pumping system. The $\mathrm{pH}$ of the pore solutions was measured with a PH2010 STANDARD pHmeter MaterLab® from Radiometer Analytical and the chemical composition identified by ICP-AES by using a Varian 720-ES ICP Optical Emission Spectrometer. Table 2 shows the composition of the electrolytes.

\subsection{Electrochemical measurements}

Mild steel ribbed rebars, $0.21 \mathrm{wt} . \% \mathrm{C}$, were used to produce the working electrode (WE). The ribs of the reinforcement were removed by using a lathe and a copper wire coated with insulating polymer was attached to a $\varnothing 1.13 \mathrm{~cm}$ WE disc $\left(\operatorname{area} \approx 1 \mathrm{~cm}^{2}\right)$. Electrical contact between the copper wire and WE was assured by silver paint. Cross-sections were mounted in cold-curing resin (Araldite ${ }^{\circledR} 2020$ epoxy) previously degassed under mechanic vacuum to avoid air bubbles at the steel/resin interface. The mounted WE was sequentially ground by SiC papers in decreasing grid size from 240 to 1200 using anhydrous ethanol (ethanol absolute AnalaR NORMAPUR) to reduce heating and oxidation. The initial heterogeneous microstructure of the as-received ribbed steel rebar and the resulting homogeneous ferrite and pearlite microstructure of WE after lathing are presented in Fig. 2.

After polishing, the samples were dried with a delicate task wipe, immediately immersed in the electrolyte, and the electrochemical measurements launched. A lid-protected $250-\mathrm{mL}$ electrochemical cell was used to perform open-circuit potential readings $\left(E_{\text {ocp }}\right)$, linear polarization resistance tests (LPR), and electrochemical impedance spectroscopy measurements (EIS). The counter-electrode was a platinum grid and a mercury/mercury oxide electrode filled with $\mathrm{NaOH} 1 \mathrm{M}$ solution (XR400, Radiometer Analytical) was used as reference instead of saturated calomel electrode (SCE). This choice was taken to avoid chloride contamination from reference electrode into the solution, which could impair the 
passivation. Electrochemical measurements were performed periodically at open-circuit conditions for 7 days. Potential value readings, LPR $\left(E= \pm 10 \mathrm{mV} v s . E_{o c p}\right.$; scan rate of 10 $\left.\mathrm{mV} \cdot \mathrm{min}^{-1}\right)$, and EIS $\left(\Delta E=10 \mathrm{mV}_{\mathrm{rms}}\right.$ sine wave signals $v s . E_{o c p} ; 10^{4} \mathrm{~Hz}$ to $10^{-2} \mathrm{~Hz}, 13$ points per decade) were carried out by using a BioLogic potentiostat SP-300. EC-Lab software was used to treat the experimental electrochemical data. All measurements were carried out at 20 $\pm 1{ }^{\circ} \mathrm{C}$ without stirring, conditions commonly observed for steel embedded in concrete. A small hole on the lid of the electrochemical cell ensured the oxygen renewal. Both the $\mathrm{pH}$ and the total volume of the electrolyte prior and at the end of 7-day testing period were measured for all the experiments. Results did not show any significant difference through the test duration indicating that both evaporation and carbonation were negligible. Each test was repeated once to ensure reproducibility of the results. After the electrochemical measurements, the interface between the resin and the WE was inspected using an optical microscope and no signs of crevice corrosion was detected.

\subsection{X-ray photoelectron spectroscopy (XPS)}

Cross-section discs measuring $\varnothing 10 \mathrm{~mm}$ x $5 \mathrm{~mm}$ extracted from steel rebars were used in XPS analyses. The face of the substrates were polished from \#240 up to \#1200 SiC under anhydrous ethanol to reduce heating and air oxidation. After polishing, the samples were put in a beaker with a large volume of anhydrous ethanol for 5 min under ultrasonic agitation, dried with a delicate task wipe, and then immediately immersed in the appropriate leached aqueous solution in sealed containers to avoid carbonation and evaporation. Here again, the $\mathrm{pH}$ and the total volume of the electrolyte into the container prior and at the end of 1 and 2 days of the carbon steel immersion did not show any significant evolution, indicating that negligible evaporation and carbonation occurred. Specimens were taken out after 1 and 2 days of immersion, rinsed with anhydrous ethanol and dried with an inert gas. This protocol was used to wash out the elements, which do not compose the passive layer. The samples were 
then transferred directly to the fore-chamber of an XPS spectrometer and purged with argon gas before being transferred to the analytical chamber for examination.

A Vacuum Generator XR3E2 apparatus with a Mg-Ka X-ray source (characteristic energy $\mathrm{hv}=1273.6 \mathrm{~V}$ ) at $15 \mathrm{kV}$ and $20 \mathrm{~mA}$ operating conditions was used to perform the XPS measurement. In this case, a hemispherical condenser Alpha 110 of Thermo Scientific was used as electron analyzer, being the pressure in the analytical chamber less than $10^{-10}$ mbar and the analyzed area about $4 \mathrm{~mm}^{2}$.

A constant pass of $40 \mathrm{eV}, 0.5 \mathrm{eV}$ of resolution, was used to record the survey spectra in a binding energy range from 0 to $1100 \mathrm{eV}$. Specific spectra were obtained with $0.1 \mathrm{eV}$ of resolution for $\mathrm{Fe}_{2 p}$ and $\mathrm{C}_{1 \mathrm{~s}}$ orbitals with acquisition angles of $30^{\circ}$ and $90^{\circ}$. All results were calibrated with respect to the position of the $\mathrm{C}_{1 \mathrm{~s}}$ peak, set as $285.0 \mathrm{eV}$.

Curve fitting of $\mathrm{Fe} 2 p$ spectra was performed to quantify and to decompose the contribution of each compound under interest. In this case, the criteria to select Fe-compounds were based on the binding energies of Fe-based compounds reported in the literature [18-21], and considering what have been reported for mild steel passivation in alkaline solutions [2224]. Also, because the ambiguity related to the identification of adjacent peaks with energy difference inferior to $1 \mathrm{eV}$, only the peaks reported in Table $\mathbf{3}$ were considered for fitting using Shirley baseline where mild steel substrate was assimilated to metallic iron $\left(\mathrm{Fe}^{\circ}\right)$ and the passive film composed of both lower $\left(\mathrm{Fe}_{3} \mathrm{O}_{4}, \mathrm{FeO}\right)$ and higher oxidation-rich $\left(\mathrm{Fe}_{2} \mathrm{O}_{3}\right.$, $\mathrm{FeOOH}$ ) compounds.

\section{Results and Discussion}

\subsection{Open circuit potential and LPR results}

Fig. 3 shows the open-circuit potential $\left(E_{o c p}\right)$ evolution of steel immersed in naturally aerated OPC and BYF solutions. All the recorded potential values are presented versus the 
commonly used saturated calomel electrode reference (SCE) instead of the mercury/mercury oxide in $1 \mathrm{M} \mathrm{NaOH}$ electrode. The change in $E_{o c p}$ was consistent in repeated tests.

For both OPC and BYF electrolytes, the $E_{o c p}$ tends towards more noble values with the progress of the immersion time. The initial steep increase of the steel potential indicates oxide film formation and thickening following an asymptotical-like tendency to the steady-state value after about 2 to 3 days in BYF electrolyte and 5 to 6 days in OPC electrolyte. These two stages of the potential evolution with an exponential decay function are often verified for steel passivation in alkaline solutions $[25,26]$, and the recorded values of potential are consistent with other works performed on carbon steel in alkaline solution where the typical potential values are ranged between -200 and $-300 \mathrm{mV}_{\text {SCE }}[27,28]$.

Although the curves exhibit similar trends, the steel immersed in OPC solution shows potential values shifted to more negative values compared with those for steel in BYF medium. This difference can be ascribed to the OPC and BYF chemical compositions (Table 2). The effect of the calcium hydroxide, sulfate, and hydroxyl concentrations on the $E_{o c p}$ evolution of steel immersed in synthetic pore solutions during the first hours has been studied by Haleem et al. [29,30]. It has been shown that higher calcium hydroxide, sulfate, and hydroxyl concentrations induce lower $E_{\text {ocp }}$ values as it was the case in the present study. Moreover, the corrosion potential corresponds to the intersection of the cathodic curve for the reduction of oxygen and the anodic curve for iron oxidation [31]. Higher oxygen availability tends to intersect the anodic curve at higher potential values while a decrease of oxygen availability results in lower potential values. In this sense, it is worth noticing that there is a correlation between the oxygen solubility and the ionic strength (Is), where the oxygen solubility in high ionic strength solutions is lower [32,33]. OPC solution presents a higher Is than the BYF solution $(0.122 \mathrm{~mol} / \mathrm{L}$ against $0.072 \mathrm{~mol} / \mathrm{L}$, respectively), therefore, the lower 
oxygen availability of OPC solution may explain why the potential evolution of the steel immersed on it is lower than the evolution of steel in BYF solution.

The evolution of the polarization resistance, $R_{p}$, and of the calculated corrosion current density, $i_{\text {corr }}$, of the steel immersed in OPC and BYF solutions are shown in Fig. 4a and b, respectively. $i_{\text {corr }}$ values have been determined using the Stern-Geary equation, $i_{\text {corr }}=B / R_{p}$, with $B=52 \mathrm{mV}$. This value, previously proposed in the literature for OPC cement matrices [34], has been held in the present paper after an intensive study confirmed its suitability also for BYF systems [16].

The first measurement was performed after $5 \mathrm{~h}$ of immersion. At this time, the $R_{p}$ values of the steel in both OPC and BYF electrolytes were about $200 \mathrm{k} \Omega . \mathrm{cm}^{2}$, resulting in low but non-negligible $i_{\text {corr }}$ values. $R_{p}$ values continuously increased during the first days and the $i_{\text {corr }}$ exhibited negligible values $\left(<0.1 \mu \mathrm{A} . \mathrm{cm}^{-2}\right)$ in less than $24 \mathrm{~h}$, suggesting spontaneous and rapid steel passivation. For steel immersed in the BYF solution, there was a rapid increase of the $R_{p}$ values during the first $24 \mathrm{~h}$, then a slower increase. With the OPC solution, the increase of $R_{p}$ was more gradual over the first 5 days of immersion. After stabilization, the $R_{p}$ values were finally similar regardless of the electrolyte (between 1200 and $1350 \mathrm{k} \Omega . \mathrm{cm}^{2}$ ).

The high alkalinity of the concrete pore solution is an essential prerequisite to ensure passivation of steel rebars as predicted by Pourbaix diagram, being the protectiveness of the passive film affected by the $\mathrm{pH}[35]$. Above $\mathrm{pH}=10.5$, an increase in alkalinity decreases the corrosion rate because iron becomes increasingly passive in presence of dissolved oxygen [36,37]. The OPC solution has higher $\mathrm{pH}$ than that of BYF solution (13.2 against 12.9, Table 2). From the $\mathrm{pH}$ values, the OPC solution should be more passivating and the carbon steel immersed on it was expected to present a higher increase of $R_{p}$ over time than the carbon steel passivation in BYF solution. However, an opposite behavior was observed. Besides the $\mathrm{pH}$, 
different studies demonstrated the impact of the pore solution chemistry on the electrochemical responses of steel in alkaline media[2-5]. Mancio et al. [38,39] evaluated the passive film formation on carbon steel in alkaline solution with different alkalinity and $I s$. As expected, for a fixed $I s$, a decrease of the $\mathrm{pH}$ yields to a decrease of the $R_{p}$. However, the study also found that the effect of $\mathrm{pH}$ on the passivation is dependent on the Is: a decrease of the $\mathrm{pH}$ in a range of 13 to 11 with a decrease of the $I s$ between $10^{-1}$ to $10^{-5} \mathrm{~mol} / \mathrm{L}$ may result in the increase of the $R_{p}$ values. Thus, the fact that BYF solution has lower $\mathrm{pH}$ and $I s$ values than OPC solution may explain why the carbon steel immersed in BYF solution passivates faster than the carbon steel immersed in OPC solution. Moreover, since electrolytes with lower Is exhibit superior oxygen solubility $[32,33]$, the higher oxygen availability in the BYF solution is an important advantage for the passive film nucleation and thickening compared to the passivation in OPC solution.

\subsection{EIS measurements}

Fig. 5 shows the evolution of the Nyquist plots and the Bode diagrams with immersion time in BYF and OPC solutions; replicate specimens show similar results and they were not plotted for a better visualization of the diagrams.

Similar trends are observed regardless of the media, i.e., the extrapolated diameter of the capacitive loop increases continuously (a continuous increase of $|Z|$ ) suggesting that the immersion time enhances the corrosion resistance. This is consistent with the OCP and LPR measurements that show a progressive increase of $E_{o c p}$ and $R_{p}$ over time. A deeper analysis of the EIS spectra is performed with the help of electrochemical equivalent circuits (EEC).

Engelhaldt et al. [40] have shown that, in case of passive iron, the simplest equivalent circuit, i.e., a parallel arrangement of a resistance and a capacitor (or a constant phase element, CPE), adequately describes the EIS behavior of passivated metals. Consequently, the 
properties of the overall interface can be represented by this simple parallel arrangement in series with a pure resistor, the modified Randle's circuit, Fig. 6, where $R e$ is the electrolyte resistance, $R_{p}$ is the polarization resistance, and $Q$ is the non-ideal overall CPE, which reflects the capacitance-like response from the whole interface (passive film, double-layer relaxation, faradaic reactions, etc). As this single $Q$ element represents the overall apparent non-ideal capacitive behavior, the characteristic values of $Q$ related to the passive film only cannot be obtained separately. It is worth noticing that a hierarchically-arranged two-time constant EEC has also been evaluated for the fitting of the experimental results. However, the obtained parameters and the quality of the fitting itself — represented by the ratio $\chi^{2} /|\mathrm{Z}|$, see below — were poorer than for the modified Randle's one that was then held for the EIS analysis.

A deeper insight of the CPE behavior comes from the plot of the imaginary part of the electrochemical impedance with frequency, as displayed in Fig. 7a and b [41,42]. The wide frequency range of linear decay seems actually to be related to a single CPE behavior, in other words, a single-time constant. This is confirmed by the analysis of effective $\alpha\left(\alpha_{\mathrm{eff}}\right)$, which is an alternative representation of CPE behavior to highlight the presence of relaxations processes for a given frequency range [43] and is calculated according to Eq. 1:

$$
\alpha_{e f f}(f)=\left|\frac{\operatorname{dlog}\left|Z_{i}(f)\right|}{\operatorname{dlog} f}\right|
$$

Fig. 7c and $\mathbf{d}$ clearly show the presence of a single time constant $\left(\alpha_{\mathrm{eff}}\right.$ constant value for approximately 3 decades) related to a constant phase element, $Q$, which appears since the first day and is present up to 7 days of steel immersion in OPC and BYF solutions. The slopes at low frequencies are similar regardless of the media (OPC and BYF) and constant with the immersion time. Values of $\alpha$ of about 0.92 for all cases indicate a clear capacitive-like behavior throughout the EIS survey. 
The proposed model in Fig. 6 seems to be able to afford a coherent interpretation of the EIS results and was thus held for the fitting of the EIS data in Fig. 5. Results are listed in Table 4. Normalized chi-square of the data fitting $\left(\chi^{2 /|Z|}\right)$, which represents the convergence level of the fitted results with the experimental data, was calculated by the software BioLogic EC-Lab V11.01. $\chi^{2} /|\mathrm{Z}|$ values inferior to $10^{-3}$ were found during EIS data treatment, indicating satisfactory fitting level.

In the different tests performed in OPC and BYF electrolytes, the $R e$ did not evolve considerably and its values were negligible compared to the $R_{p}$ ones due to the high conductivity of ions between the reference and working electrodes. $R_{p}$ values, in turn, increased rapidly as immersion time elapsed, demonstrating that a protective layer forms and grows since the first moments thanks to the intrinsic passivating nature of both OPC and BYF solutions from cement paste cured for 28 days. As early as 3 days of immersion, $R_{p}$ reached values around $10^{6} \mathrm{k} \Omega . \mathrm{cm}^{2}$, which means corrosion rates well below $0.1 \mu \mathrm{A} . \mathrm{cm}^{-2}$. Simultaneously, the $Q$ values decreased and approached the steady-state value of $41 \mu \Omega . \mathrm{cm}^{-}$ ${ }^{2} \mathrm{~s}^{-0.94}$ for steel in OPC and $41 \mu \Omega \cdot \mathrm{cm}^{-2} \mathrm{~s}^{-0.95}$ for steel in BYF.

Using the constant phase element values $(Q$ and $\alpha), R e$, and $R_{p}$, the effective capacitance $\left(C_{\text {eff }}\right)$ can be calculated according to the following equation [44]:

$$
C_{e f f}=\left[\frac{Q}{\left(R_{e}^{-1}+R_{p}^{-1}\right)^{\{\alpha-1\}}}\right]^{\frac{1}{\alpha}}
$$

The effective capacitances calculated from the values listed in Table $\mathbf{4}$ are ranged from 31 to $25 \mu \mathrm{F} . \mathrm{cm}^{-2}$ for steel in OPC solution and from 45 to $28 \mu \mathrm{F} . \mathrm{cm}^{-2}$ for steel in BYF solution. Assuming that these overall apparent capacitance values include the contribution of the passive layer space-charge capacitance $\left(C_{o x}\right)$ and the double-layer capacitance $\left(C_{d l}\right)$ in a 
series arrangement, if the capacitance of the passive film is small compared to the doublelayer capacitance, as expected, the overall capacitances obtained from EIS data are dominated by the response of the passive film [45]. In this case, the passive film thickness can be calculated from Eq. 3, which is valid for the parallel-plate capacitor model of a homogeneous oxide layer, assimilating the overall effective capacitance to the capacitance of the protective oxide layer $\left(C_{o x}\right)$ :

$$
d_{o x}=\frac{\varepsilon_{o} \varepsilon_{r}}{C_{o x}}
$$

where $\varepsilon_{0}$ is the vacuum permittivity $\left(\varepsilon_{0}=8.85 \times 10^{-12} \mathrm{~F} / \mathrm{m}\right)$ and $\varepsilon_{r}$ is the relative dielectric constant (taken as $\varepsilon_{r}=12$, the dielectric constant of $\mathrm{Fe}_{2} \mathrm{O}_{3}$ [46]). The calculated thickness of steel immersed in OPC solution ranges from 3.4 to $4.2 \AA$ and from 2.4 to $3.8 \AA$ for steel passivated in BYF solution. Even if these values are qualitatively consistent (thickening of the film with time), they are up to one order of magnitude inferior to the values of the passive layer reported in the literature obtained by in-situ techniques [22-24].

This discrepancy can be related to the fact that the double-layer capacitance may not be negligible, or that the dielectric constant of the actual passivating film composed of iron oxyhydroxides and oxides is not well established. Besides the capacitive contribution of the passive film, studies reported the formation of particles on the steel surface due to the local heterogeneous nucleation and growth of minerals (e.g. $\mathrm{Ca}(\mathrm{OH})_{2}$ and other Ca-rich compounds) [22,23], which may contribute to the overall capacitive response of the system. In addition, the air exposure of the steel surface during the electrochemical cell assemblage may introduce a thin carbon layer on the steel surface.

Calculation of the thickness of the passive layer by Eq. 3 from the EIS data is an indirect method and, therefore, susceptible to the accumulation of the errors mentioned before. It is worth noticing, however, that the evolution of the polarization resistance and the capacitive 
response of the samples during immersion gave a comparative view of steel immersed in OPC and BYF solutions. Indeed, despite a mostly qualitative analysis of EIS, due to the system response collapsed to a single apparent time constant and to the restrictions to a more quantitative analysis of the film thickness, it was possible to unambiguously demonstrate that, unlikely to previous studies, BYF, as well as OPC cement-based matrices, do have an intrinsic passivating ability regarding mild steel.

A final remark concerns the fact that these results illustrate the difficulty of extracting reliable parameters from the fitting of EIS through EEC. This is a widely used procedure that must be carried out very carefully. EEC must be seen as what they actually are: a simple datahandling tool with which we try to make the interface's response to a perturbation signal match the expected behavior of elements of a linear electrical circuit and not a straightforward physical description of the interface.

\subsection{XPS: characterization of the passive films}

The previous electrochemical results pointed out that the protectiveness of the passive layer formed on the steel immersed in OPC and BYF pore solutions is similar. However, the electrochemical techniques did not provide detailed information about the compositional characteristics of the passive film. Furthermore, as discussed before, the calculation of the thickness of the passive film from the EIS data is potentially unreliable. Considering these difficulties, XPS was conducted on the different samples as soon as the electrochemical results started to indicate negligible corrosion rates, i.e., after 1 and 2 days of immersion.

The general survey spectra of the steel immersed in OPC and BYF solutions, Fig. 8, indicate the presence of $\mathrm{C}, \mathrm{Ca}, \mathrm{Fe}$, and $\mathrm{O}$. Other elements present in the pore solution such as $\mathrm{Na}, \mathrm{K}, \mathrm{Al}, \mathrm{S}$, and $\mathrm{Si}$ are not expected to be present in passive layer and were washed out prior to XPS during the rinsing step. The expressive $\mathrm{C}$ peak is related to both the adsorbed ethanol 
and its evaporation residue remaining on the specimen surface upon drying. Calcium compounds are associated to precipitated mineral scales, which are a common occurrence in steel passivation studies in concrete pore solutions [23]. Consistently, as seen in Fig. 8, these Ca-rich compounds are not present in steel exposed to air. Iron oxides/oxyhydroxides, hydrocarbons, and calcium-based mineral scales accounts to the oxygen signal. Iron peaks are attributed to the steel substrate and to the iron oxides and iron oxyhydroxides products, which are the scope of this study.

Specific Fe spectra at $90^{\circ}$ and $30^{\circ}$ for steel immersed for 1 and 2 days in OPC and BYF extracts are shown in Fig. 9 and 10, respectively. The large broad peak of the Fe $2 p_{3 / 2}$ is ascribed to iron oxides and oxyhydroxides while the much smaller peak allocated at lower binding energies is associated to metallic iron. The presence of the metallic iron peak in all samples regardless of the media and immersion time indicates that the layer thickness on the steel substrate is inferior to $10 \mathrm{~nm}$, the maximum escape depth of photoelectrons. However, for the steel specimen exposed to air, Fig. 9a and $\mathbf{b}$, it is clearly seen a higher intensity of the iron metallic peak Fe-1 indicating thinner layer formation on the air-exposed steel substrate compared to those formed on steel immersed in OPC and BYF solutions.

Steel immersed in OPC and BYF solutions exhibit similar spectra at $90^{\circ}$ and $30^{\circ}$ after 1 day, Fig. 9, and 2 days, Fig. 10, of immersion. This suggests that the chemical composition and the amount of iron compounds, therefore the average thickness of the iron oxide layer, of the passive film on the steel substrate immersed in OPC and BYF solutions are similar.

The relative fraction of each iron oxide and oxyhydroxide compounds can be calculated from the ratio between each individual area and the sum of the areas of the iron oxide and oxyhydroxide compounds. Different iron compounds have different resistance against corrosion, being the $\mathrm{Fe}-\mathrm{II}-$-rich ones $\left(\mathrm{FeO}\right.$ and $\left.\mathrm{Fe}_{3} \mathrm{O}_{4}\right)$ recognized as the most resistant one [47-49]. Fig. 11 reveals that the passive layer formed in OPC and BYF solutions present 
almost the same proportion of low $\left(\mathrm{FeO}\right.$ and $\left.\mathrm{Fe}_{3} \mathrm{O}_{4}\right)$ and high $\left(\mathrm{Fe}_{2} \mathrm{O}_{3}\right.$ and $\left.\mathrm{FeOOH}\right)$ oxidation level compounds (ca 1/3 and 2/3, respectively). Since Fe-III compounds are more likely to have been in direct contact with the solution, the film is probably composed of an inner Fe-IIrich highly protective oxide layer and an outer Fe-III-rich less protective one. The similarities in the chemical composition of the passive film shown in Fig. 11 indicate that the protectiveness of the passive film formed on the carbon steel immersed in OPC and BYF is comparable. This is of importance because in the presence of aggressive species such as chlorides, if it is not considered the role of the hydroxyl concentration in the solution, both passive films formed on steel immersed in OPC and BYF solutions isare expected to exhibit similar resistance against pitting corrosion.

The thickness of the passive film, $D$, was calculated according to the following equation [50], assuming an uniform iron-oxygen-rich film on the steel sample:

$$
D=\lambda_{o x}^{F e} \cdot \cos (\theta) \cdot \ln \left(\frac{I_{o x}^{F e}}{I_{m}^{F e}} \cdot \frac{N_{m}^{F e}}{N_{o x}^{F e}} \cdot \frac{\lambda_{m}^{F e}}{\lambda_{o x}^{F e}}+1\right)
$$

where $I_{m}^{F e}$ and $N_{m}^{F e}$ are the intensity and the atom density of metallic iron, respectively, while $I_{o x}^{F e}$ and $N_{o x}^{F e}$ are the intensity and the atom density of iron-rich-oxygen compounds, respectively; the electron inelastic mean free path in metallic iron, $\lambda_{m}^{F e}$, and in iron-oxygenrich compounds, $\lambda_{o x}^{F e}$, can be calculated from [51]:

$$
\begin{aligned}
& \lambda_{m}^{F e}=0.41 \cdot\left(a_{m}\right)^{3 / 2} \cdot\left(E_{k}\right)^{1 / 2} ; a_{m}=\left(\frac{1}{N_{m}^{F e}}\right)^{1 / 3} \\
& \lambda_{o x}^{F e}=0.72 \cdot\left(a_{o x}\right)^{3 / 2} \cdot\left(E_{k}\right)^{1 / 2} ; a_{o x}=\left(\frac{1}{N_{o x}^{F e}}\right)^{1 / 3}
\end{aligned}
$$

with $E_{k}$ the kinetic energy of the considered photoelectrons, $779 \mathrm{eV}$ for iron, and $a$ the mean distance between two atoms. For calculations, it was considered $N_{m}^{F e}=84$ atom $/ \mathrm{nm}^{3}, N_{o x}^{F e}=$ 38 atom $/ \mathrm{nm}^{3}$ [51], and the intensities $I_{m}^{F e}$ and $I_{o x}^{F e}$ at $0^{\circ}$ using the procedure described in Ghods et al. works [22,23]. 
The calculated thicknesses of the passive layer formed on the steel immersed for 1 and 2 days in OPC and BYF solutions are summarized in Table 5. As might be expected from the electrochemical results of steel immersed in BYF and OPC pore solutions, steel readily starts to passivate when immersed in these media with the formation of a passivating layer of about $5 \mathrm{~nm}$ regardless of the media and immersion time of 1 and 2 days.

As a final remark, it is worth reminding that experiments in the present paper have been performed with leachates and not actual pore solutions — hardly obtainable experimentally. As in any simplified representation of a complex physical system, leachates are nothing more than an experimentally feasible reproduction of the actual chemistry we were trying to investigate. In other words, this protocol can be accepted as a reasonable approximation, but it must be borne in mind that the interpretation has been objectively conducted from results obtained with an electrolyte that is not the actual pore solution. Strictly speaking, the conclusions raised here are to be analyzed in the context of our experimental conditions, even if they seem to constitute a robust evidence of BYF passivating ability. Much work is still needed from experimental, theoretical and modelling points of view for these results to be fully and unambiguously validated and, consequently, for BYF to be a reliable alternative to OPC in terms of reinforcing steel passivation / corrosion behavior.

\section{Conclusions}

Both tested BYF and OPC electrolytes enabled effective passivation of mild steel in less than $24 \mathrm{~h}$ of immersion, with a similar evolution of the interface steel/solution. The protective passive layer formed in BYF and OPC solutions was about $5 \mathrm{~nm}$ thick consisting of a similar fraction of Fe-II and Fe-III compounds as determined by XPS measurements. The use of the modified Randle's circuit to interpret the EIS data was not able to distinguish, in our study, the different capacitances from the steel/electrolyte interface. This lack of resolution led to 
overestimated capacitance values and, consequently, to an underestimation of the thickness of the passive film, which was, thus, more accurately determined from XPS measurements.

Even if some previous studies claimed that early BYF pore solution could be potentially corrosive, this work showed that as the hydration of BYF progresses, its pore solution may be as protective as that found in Portland equivalents at 28 days of curing. These results might increase the domain of application of BYF cement, leading to the production of low-cost reinforced concrete structures with reduced $\mathrm{CO}_{2}$ footprint.

\section{Acknowledgements}

The authors gratefully acknowledge the financial support of the Brazilian institution CNPq (grant number 229886/2013-2), of the French institution ANRT (grant number 2013/1440), and of the LafargeHolcim group.

\section{Data availability}

The raw/processed data required to reproduce these findings cannot be shared at this time as the data also forms part of an ongoing study. 


\section{References}

[1] M.A.G. Aranda, A.G. De la Torre, Sulfoaluminate cement, in: F. Pacheco-Torgal, S. Jalali, J. Labrincha, V.M. John (Eds.), Eco-Efficient Concr., Woodhead Publishing, 2013: pp. 488-522. doi:10.1533/9780857098993.4.488.

[2] A. Poursaee, C.M. Hansson, Reinforcing steel passivation in mortar and pore solution, Cem. Concr. Res. 37 (2007) 1127-1133. doi:10.1016/j.cemconres.2007.04.005.

[3] P. Ghods, O.B. Isgor, G. McRae, T. Miller, The effect of concrete pore solution composition on the quality of passive oxide films on black steel reinforcement, Cem. Concr. Compos. 31 (2009) 2-11. doi:10.1016/j.cemconcomp.2008.10.003.

[4] L. Véleva, M. Cebada, Model solutions of concrete environment and effect of chloride ions on the electrochemical corrosion behavior of reinforcing mild steel, in: S.W. Dean, G. Hernandez-Duque Delgadillo, J.B. Bushman (Eds.), Mar. Corros. Trop. Environ., ASTM International, 100 Barr Harbor Drive, PO Box C700, West Conshohocken, PA 19428-2959, 2000: pp. 170-189. doi:10.1520/STP13561S.

[5] L. Veleva, M.A. Alpuche-Aviles, M.K. Graves-Brook, D.O. Wipf, Comparative cyclic voltammetry and surface analysis of passive films grown on stainless steel 316 in concrete pore model solutions, J. Electroanal. Chem. 537 (2002) 85-93. doi:10.1016/S0022-0728(02)01253-6.

[6] H. Luo, H. Su, C. Dong, X. Li, Passivation and electrochemical behavior of 316L stainless steel in chlorinated simulated concrete pore solution, Appl. Surf. Sci. 400 (2017) 38-48. doi:10.1016/j.apsusc.2016.12.180.

[7] M. Liu, X. Cheng, X. Li, Z. Jin, H. Liu, Corrosion behavior of Cr modified HRB400 steel rebar in simulated concrete pore solution, Constr. Build. Mater. 93 (2015) 884 890. doi:10.1016/j.conbuildmat.2015.05.073.

[8] M. Saremi, E. Mahallati, A study on chloride-induced depassivation of mild steel in 
simulated concrete pore solution, Cem. Concr. Res. 32 (2002) 1915-1921. doi:10.1016/S0008-8846(02)00895-5.

[9] B. Huet, V. L'Hostis, F. Miserque, H. Idrissi, Electrochemical behavior of mild steel in concrete : Influence of $\mathrm{pH}$ and carbonate content of concrete pore solution, Electrochim. Acta. 51 (2005) 172-180. doi:10.1016/j.electacta.2005.04.014.

[10] M. Liu, X. Cheng, X. Li, T.J. Lu, Corrosion behavior of low-Cr steel rebars in alkaline solutions with different $\mathrm{pH}$ in the presence of chlorides, J. Electroanal. Chem. 803 (2017) 40-50. doi:10.1016/j.jelechem.2017.09.016.

[11] E. Volpi, A. Olietti, M. Stefanoni, S.P. Trasatti, Electrochemical characterization of mild steel in alkaline solutions simulating concrete environment, J. Electroanal. Chem. 736 (2015) 38-46. doi:10.1016/j.jelechem.2014.10.023.

[12] E. Gartner, T. Sui, Alternative cement clinkers, Cem. Concr. Res. (2017). doi:10.1016/j.cemconres.2017.02.002.

[13] V. Morin, P. Termkhajornkit, B. Huet, G. Pham, Impact of quantity of anhydrite, water to binder ratio, fineness on kinetics and phase assemblage of belite-ye'elimite-ferrite cement, Cem. Concr. Res. 99 (2017) 8-17. doi:10.1016/j.cemconres.2017.04.014.

[14] I. Janotka, L. Krajči, A. Ray, S.C. Mojumdar, The hydration phase and pore structure formation in the blends of sulfoaluminate-belite cement with Portland cement, Cem. Concr. Res. 33 (2003) 489-497. doi:10.1016/S0008-8846(02)00994-8.

[15] D. Kalogridis, G.C. Kostogloudis, C. Ftikos, C. Malami, Quantitative study of the influence of non-expansive sulfoaluminate cement on the corrosion of steel reinforcement, Cem. Concr. Res. 30 (2000) 1731-1740. doi:10.1016/S00088846(00)00277-5.

[16] G.Y. Koga, B. Albert, V. Roche, R.P. Nogueira, A comparative study of mild steel passivation embedded in Belite-Ye'elimite-Ferrite and Porland cement mortars, 
Electrochim. Acta. 261 (2018) 66-77. doi:10.1016/j.electacta.2017.12.128.

[17] R.S. Barneyback, S. Diamond, Expression and analysis of pore fluids from hardened cement pastes and mortars, Cem. Concr. Res. 11 (1981) 279-285. doi:10.1016/00088846(81)90069-7.

[18] P.C.J. Graat, M.A.J. Somers, Simultaneous determination of composition and thickness of thin iron-oxide films from XPS Fe 2p spectra, Appl. Surf. Sci. 100-101 (1996) 3640. doi:10.1016/0169-4332(96)00252-8.

[19] M. Descostes, F. Mercier, N. Thromat, C. Beaucaire, M. Gautier-Soyer, Use of XPS in the determination of chemical environment and oxidation state of iron and sulfur samples: Constitution of a data basis in binding energies for $\mathrm{Fe}$ and $\mathrm{S}$ reference compounds and applications to the evidence of surface species of an oxidized py, Appl. Surf. Sci. 165 (2000) 288-302. doi:10.1016/S0169-4332(00)00443-8.

[20] T. Yamashita, P. Hayes, Analysis of XPS spectra of Fe2+ and Fe3+ ions in oxide materials, Appl. Surf. Sci. 254 (2008) 2441-2449. doi:10.1016/j.apsusc.2007.09.063.

[21] M.C. Biesinger, B.P. Payne, A.P. Grosvenor, L.W.M. Lau, A.R. Gerson, R.S.C. Smart, Resolving surface chemical states in XPS analysis of first row transition metals, oxides and hydroxides: Cr, Mn, Fe, Co and Ni, Appl. Surf. Sci. 257 (2011) 2717-2730. doi:10.1016/j.apsusc.2010.10.051.

[22] P. Ghods, O. Burkan Isgor, F. Bensebaa, D. Kingston, Angle-resolved XPS study of carbon steel passivity and chloride-induced depassivation in simulated concrete pore solution, Corros. Sci. 58 (2012) 159-167. doi:10.1016/j.corsci.2012.01.019.

[23] P. Ghods, O.B. Isgor, J.R. Brown, F. Bensebaa, D. Kingston, XPS depth profiling study on the passive oxide film of carbon steel in saturated calcium hydroxide solution and the effect of chloride on the film properties, Appl. Surf. Sci. 257 (2011) 46694677. doi:10.1016/j.apsusc.2010.12.120. 
[24] F. Miserque, B. Huet, G. Azou, D. Bendjaballah, V. L'Hostis, X-ray photoelectron spectroscopy and electrochemical studies of mild steel FeE500 passivation in concrete simulated water, J. Phys. IV. 136 (2006) 89-97. doi:10.1051/jp4:2006136010.

[25] M. Sánchez, J. Gregori, C. Alonso, J.J. García-Jareño, H. Takenouti, F. Vicente, Electrochemical impedance spectroscopy for studying passive layers on steel rebars immersed in alkaline solutions simulating concrete pores, Electrochim. Acta. 52 (2007) 7634-7641. doi:10.1016/j.electacta.2007.02.012.

[26] M. Liu, X. Cheng, X. Li, Y. Pan, J. Li, Effect of Cr on the passive film formation mechanism of steel rebar in saturated calcium hydroxide solution, Appl. Surf. Sci. 389 (2016) 1182-1191. doi:10.1016/j.apsusc.2016.08.074.

[27] J. Williamson, O.B. Isgor, The effect of simulated concrete pore solution composition and chlorides on the electronic properties of passive films on carbon steel rebar, Corros. Sci. 106 (2016) 82-95. doi:10.1016/j.corsci.2016.01.027.

[28] P. Ghods, O.B. Isgor, G.A. McRae, G.P. Gu, Electrochemical investigation of chlorideinduced depassivation of black steel rebar under simulated service conditions, Corros. Sci. 52 (2010) 1649-1659. doi:10.1016/j.corsci.2010.02.016.

[29] S.M. Abd El Haleem, E.E. Abd El Aal, S. Abd El Wanees, A. Diab, Environmental factors affecting the corrosion behaviour of reinforcing steel: I. The early stage of passive film formation in $\mathrm{Ca}(\mathrm{OH}) 2$ solutions, Corros. Sci. 52 (2010) 3875-3882. doi:10.1016/j.corsci.2010.07.035.

[30] S.M. Abd El Haleem, S. Abd El Wanees, E.E. Abd El Aal, A. Diab, Environmental factors affecting the corrosion behavior of reinforcing steel II. Role of some anions in the initiation and inhibition of pitting corrosion of steel in $\mathrm{Ca}(\mathrm{OH}) 2$ solutions, Corros. Sci. 52 (2010) 292-302. doi:10.1016/j.corsci.2009.09.004.

[31] A. Poursaee, C.M. Hansson, Potential pitfalls in assessing chloride-induced corrosion 
of steel in concrete, Cem. Concr. Res. 39 (2009) 391-400.

doi:10.1016/j.cemconres.2009.01.015.

[32] M. Popović, H. Niebelschütz, M. Reuß, Oxygen solubilities in fermentation fluids, Eur. J. Appl. Microbiol. Biotechnol. 8 (1979) 1-15. doi:10.1007/BF00510261.

[33] A. Schumpe, I. Adler, W.-D. Deckwer, Solubility of oxygen in electrolyte solutions, Biotechnol. Bioeng. 20 (1978) 145-150. doi:10.1002/bit.260200114.

[34] C. Andrade, C. Alonso, Test methods for on-site corrosion rate measurement of steel reinforcement in concrete by means of the polarization resistance method, Mater. Struct. 37 (2004) 623-643. doi:10.1007/BF02483292.

[35] B. Beverskog, I. Puigdomenech, Revised Pourbaix diagrams for iron at $25-300^{\circ} \mathrm{C}$, Corros. Sci. 38 (1996) 2121-2135. doi:10.1016/S0010-938X(96)00067-4.

[36] R. Shalon, M. Raphael, Influence of sea water on corrosion of reinforcement, J. Am. Concr. Inst. 55 (1959) 1251-1268.

[37] A. Bentur, S. Diamond, N.S. Berke, Steel corrosion in concrete: Fundamentals and civil engineering practice, First edit, E \& FN SPON, London, UK, 1997.

[38] M. Mancio, Electrochemical and in-situ surface-enhanced raman spectroscopy (SERS) study of passive films formed on low-carbon steel in highly alkaline environments, University of California, Berkeley, 2008.

[39] M. Mancio, G. Kusinski, P.J.M. Monteiro, T.M. Devine, S. Brossia, N.S. Berke, S.W. Dean, Electrochemical and in-situ SERS Study of Passive Film Characteristics and Corrosion Performance of 9\%Cr Microcomposite Steel in Highly Alkaline Environments, J. ASTM Int. 6 (2009) 101903. doi:10.1520/JAI101903.

[40] G.R. Engelhardt, R.P. Case, D.D. Macdonald, Electrochemical impedance spectroscopy optimization on passive metals, J. Electrochem. Soc. 163 (2016) 470476. doi:10.1149/2.0811608jes. 
[41] P. Córdoba-Torres, T.J. Mesquita, R.P. Nogueira, Toward a better characterization of constant-phase element behavior on disk electrodes from direct impedance analysis: Methodological considerations and mass transport effects, Electrochim. Acta. 92 (2013) 323-334. doi:10.1016/j.electacta.2013.01.036.

[42] M.E. Orazem, N. Pébère, B. Tribollet, Enhanced graphical representation of electrochemical impedance data, J. Electrochem. Soc. 153 (2006) B129. doi:10.1149/1.2168377.

[43] P. Córdoba-Torres, N.T.C. Oliveira, C. Bolfarini, V. Roche, R.P. Nogueira, Electrochemical impedance analysis of $\mathrm{TiO} 2$ nanotube porous layers based on an alternative representation of impedance data, J. Electroanal. Chem. 737 (2015) 54-64. doi:10.1016/j.jelechem.2014.06.034.

[44] G.J. Brug, A.L.G. van den Eeden, M. Sluyters-Rehbach, J.H. Sluyters, The analysis of electrode impedances complicated by the presence of a constant phase element, J. Electroanal. Chem. Interfacial Electrochem. 176 (1984) 275-295. doi:10.1016/S00220728(84)80324-1.

[45] J.W. Schultze, M.M. Lohrengel, Stability, reactivity and breakdown of passive films. Problems of recent and future research, Electrochim. Acta. 45 (2000) 2499-2513. doi:10.1016/S0013-4686(00)00347-9.

[46] H.R. Lide, Handbook of chemistry and physics, CRC press, New York, 1995.

[47] S. Haupt, H.H. Strehblow, Corrosion, Layer Formation, and Oxide Reduction of Passive Iron in Alkaline Solution: A Combined Electrochemical and Surface Analytical Study, Langmuir. 3 (1987) 873-885. doi:10.1021/la00078a003.

[48] A. Hugot-le Goff, J. Flis, N. Boucherit, S. Joiret, J. Wilinski, Use of raman spectroscopy and rotating split ring disk electrode for identification of surface layers on iron in 1M NaOH, J. Electrochem. Soc. 137 (1990) 2684-2690. 
[49] S. Joiret, M. Keddam, C. Rangel, H. Takenouti, Use of EIS , ring-disk electrode, EQCM and Raman spectroscopy to study the film of oxides formed on iron in $1 \mathrm{M}$ $\mathrm{NaOH}, \mathrm{Cem}$. Concr. Compos. 24 (2002) 7-15.

[50] M.P. Seah, Quantification of AES and XPS, in: D. Briggs, M.P. Seah (Eds.), Prat. Surf. Anal., $2^{\circ}$ edition, Wiley, 1990: pp. 201-251.

[51] M.P. Seah, W.A. Dench, Quantitative electron spectroscopy of surfaces: a stan- dard data base for electron inelastic mean free paths in solids, Surf. Interface Anal. 1 (1972) $2-11$. 


\section{List of captions}

Fig. 1 Main phases at 28 days of hydration of OPC and BYF cement pastes with water to cement ratio of 0.50 . AFm is shorthand for a family of hydrated calcium aluminate phases structurally related to hydrocalumite and occurring mainly in hydrated cement paste. $\mathrm{Si}-\mathrm{Hg}$ and C-S-H stand for siliceous hydrogarnet and calcium-silicate hydrate, respectively.

Fig. 2 Cross-sectional optical micrographs (500x, after Nital 2\% etching) taken at a) the edge (martensite) and the core ( $\alpha$-Fe and pearlite) of the as-received ribbed steel rebar, and $b$ ) taken at the edge and core of the steel after rib removal, showing in both cases a ferrite plus pearlite microstructure with a slight different in grain refinement. Carbon and sulfur content determined by high-frequency and infrared detection. Other elements determined by spark optical emission spectrometry. Central image: assembled working-electrode.

Fig. 3 Increase of the $E_{o c p}$ values with time of steel immersed in OPC and BYF solutions. Numbers \#1 and \#2 stand for two different samples analyzed in the same condition to verify the repeatability.

Fig. 4 Corrosion resistance evolution in terms of $R_{p}$ (solid dots) and the corresponding $i_{\text {corr }}$ (open dots) values for a) two steel samples immersed in OPC solution, and b) two steel samples in BYF solution. The $i_{\text {corr }}$ are calculated from the Stern-Geary equation, assuming $B$ $=52 \mathrm{mV}$.

Fig. 5 Nyquist plots for steel immersed in a) OPC solution, and c) BYF solution. Bode plots for steel immersed in b) OPC solution, and d) BYF solution. The Bode plots for 3, 4, 5, and 6 days are not included to better visualize the trends.

Fig. 6 Equivalent circuit with one-time constant in series with a resistor (referred to as modified Randle's circuit). 
Fig. 7 Imaginary part of the impedance as a function of the frequency of a) steel in OPC extract and b) steel immersed in BYF extract. Constant phase element behavior between 1 and 7 days of c) steel immersed in OPC extract, and d) steel immersed in BYF extract. Horizontal dashed lines represent the saturation mean values considered for $\alpha_{\text {eff. }}$

Fig. 8 Survey XPS spectra at $90^{\circ}$ of steel embedded in OPC and BYF extracts during a) 1 day, and b) 2 days. The spectra of steel exposed to air during $5 \mathrm{~min}$ is also shown.

Fig 9 Specific Fe $2 p$ XPS spectra and their decompositions for a) and b) steel exposed to air for 5 min., c) and d) steel immersed for 1 day in OPC solution, and e) and f) steel immersed in BYF solution for 1 day.

Fig. 10 Specific Fe $2 p$ XPS spectra and their decompositions for a) and b) steel immersed in OPC solution for 2 days, c) and d) steel immersed in BYF solution for 2 days.

Fig. 11 Similarity of the relative proportions of iron compounds considering the XPS specific $\mathrm{Fe} 2 p$ spectra at $90^{\circ}$ of steel immersed in OPC and BYF electrolytes. 
Table 1 Characteristics of the binders of the study (Rietveld quantitative phase analysis, readily soluble alkalis, and Blaine specific surface according to NF EN 196-6).

\begin{tabular}{|c|c|c|c|}
\hline \multicolumn{4}{|c|}{ Rietveld Quantitative Phase Analysis g / 100 g cement } \\
\hline Phases & OPC & Phases & $B Y F$ \\
\hline Alite, $\mathrm{Ca}_{3} \mathrm{SiO}_{5}$ & 60.2 & Ye'elimite, $\mathrm{Ca}_{4} \mathrm{Al}_{6} \mathrm{O}_{12}\left(\mathrm{SO}_{4}\right)$ & 31.1 \\
\hline$\beta$-Belite, $\mathrm{Ca}_{2} \mathrm{SiO}_{4}$ & 17.9 & $\alpha^{\prime}$-Belite, $\mathrm{Ca}_{2} \mathrm{SiO}_{4}$ & 29.0 \\
\hline Ferrite, $\mathrm{Ca}_{2}(\mathrm{Al}, \mathrm{Fe})_{2} \mathrm{O}_{5}$ & 10.5 & $\beta$-Belite, $\mathrm{Ca}_{2} \mathrm{SiO}_{4}$ & 8.0 \\
\hline Aluminate, $\mathrm{Ca}_{3} \mathrm{Al}_{2} \mathrm{O}_{6}$ & 5.1 & Ferrite, $\mathrm{Ca}_{2}(\mathrm{Al}, \mathrm{Fe})_{2} \mathrm{O}_{5}$ & 17.7 \\
\hline Gypsum, $\mathrm{CaSO}_{4} \cdot 2\left(\mathrm{H}_{2} \mathrm{O}\right)$ & 1.8 & Anhydrite, $\mathrm{CaSO}_{4}$ & 6.5 \\
\hline Hemihydrate, $\mathrm{CaSO}_{4} \cdot 0.5\left(\mathrm{H}_{2} \mathrm{O}\right)$ & 1.8 & Gypsum, $\mathrm{CaSO}_{4} \cdot 2\left(\mathrm{H}_{2} \mathrm{O}\right)$ & 1.5 \\
\hline Calcite, $\mathrm{CaCO}_{3}$ & 1.5 & Periclase, $\mathrm{MgO}$ & 0.9 \\
\hline Periclase, $\mathrm{MgO}$ & 0.1 & Other phases (inert) & 5.9 \\
\hline Free lime, $\mathrm{CaO}$ & 1.1 & & \\
\hline
\end{tabular}

\section{Readily soluble Alkalis*}

\begin{tabular}{llll}
\hline $\mathrm{K}_{2} \mathrm{O}$ & 0.77 & $\mathrm{~K}_{2} \mathrm{O}$ & 0.36 \\
$\mathrm{Na}_{2} \mathrm{O}$ & 0.07 & $\mathrm{Na}_{2} \mathrm{O}$ & 0.02 \\
& & $\mathrm{~B}_{2} \mathrm{O}_{3} * *$ & 1.36 \\
Blaine specific surface $\left(\mathrm{cm}^{2} / \mathrm{g}\right)$ & 3680 & Blaine specific surface $\left(\mathrm{cm}^{2} / \mathrm{g}\right)$ & 4430 \\
\hline
\end{tabular}

* The soluble alkali contents represent the part of alkali that can be extracted from the cement in water for 15 minutes (analysis of the solution by ICP-AES).

** Boron content is the amount extracted in acid solution, $1 / 6 \mathrm{vol} . \mathrm{HCl}$, during $10 \mathrm{~min}$ (analysis of the solution by ICP-AES). 
Table 2 Measured total concentrations in OPC and BYF solutions used as electrolytes in electrochemical and XPS analyses.

\begin{tabular}{|c|c|c|c|c|c|c|c|c|c|}
\hline Solution & $p H$ & $\begin{array}{l}\text { Si } \\
\mathrm{mmol} / \mathrm{L}\end{array}$ & $\begin{array}{l}A l \\
\mathrm{mmol} / \mathrm{L}\end{array}$ & $\begin{array}{l}\mathrm{Ca} \\
\mathrm{mmol} / \mathrm{L}\end{array}$ & $\begin{array}{l}\text { K } \\
\mathrm{mmol} / \mathrm{L}\end{array}$ & $\begin{array}{l}\mathrm{Na} \\
\mathrm{mmol} / \mathrm{L}\end{array}$ & $\begin{array}{l}S^{a} \\
\mathrm{mmol} / \mathrm{L}\end{array}$ & $\begin{array}{l}B^{b} \\
\mathrm{mmol} / \mathrm{L}\end{array}$ & $\begin{array}{l}I \mathrm{~s}^{*} \\
(\mathrm{~mol} / \mathrm{L})\end{array}$ \\
\hline $\mathrm{OPC}^{a}$ & 13.2 & 0.018 & 0.018 & 6.04 & 204 & 16 & 0.11 & --- & 0.122 \\
\hline $\mathrm{BYF}^{\mathrm{b}}$ & 12.9 & 0.037 & 0.09 & 4.74 & 116 & 8 & 0.08 & 0.09 & 0.072 \\
\hline
\end{tabular}

$*$ Is $=$ Ionic Strength $=\frac{1}{2} \sum_{i=1}^{n} c_{i} z_{i}^{2}$, where $c_{i}$ is the molar concentration of ion $i(\mathrm{~mol} / \mathrm{L})$ and $z_{i}$ is the charge number of that ion.

${ }^{\text {a }}$ Considered in solution as $\mathrm{SO}_{4}{ }^{2-}$

${ }^{\mathrm{b}}$ Considered in solution as $\mathrm{B}(\mathrm{OH})_{4}^{-}$ 
Table 3 Peak parameters of Fe-based compounds used for XPS fitting.

\begin{tabular}{lllll}
\hline Element (core level) & Peak ID & Assignment & Peak position $( \pm 0.2)$ & FWHM $^{\boldsymbol{b}}( \pm \mathbf{0 . 2})$ \\
\hline \multirow{3}{*}{$\boldsymbol{F e}(2 \boldsymbol{p})$} & $\mathrm{Fe}-1$ & $\mathrm{Fe}^{\circ}$ & $706.5^{\mathrm{a}}$ & 1.9 \\
& $\mathrm{Fe}-2$ & $\mathrm{FeO}, \mathrm{Fe}_{3} \mathrm{O}_{4}$ & 709.0 & 2.8 \\
& $\mathrm{Fe}-3$ & $\mathrm{Fe}_{2} \mathrm{O}_{3}$ & 710.4 & 2.6 \\
& $\mathrm{Fe}-4$ & $\mathrm{FeOOH}$ & 712.2 & 3.0 \\
\hline
\end{tabular}

${ }^{\mathrm{a}} \mathrm{T}_{\mathrm{Hgt}} / \mathrm{T}_{\mathrm{Mix}} / \mathrm{T}_{\mathrm{Exp}}: 0 / 0.20 / 0.08$. The other peaks were considered symmetric.

${ }^{\mathrm{b}}$ Full width at half maximum. 
Table 4 Fitting parameters of EIS data considering the equivalent circuit in Fig. 6.

\begin{tabular}{|c|c|c|c|c|c|c|}
\hline \multirow{2}{*}{ Sample } & \multirow{2}{*}{$\begin{array}{l}\text { Time } \\
\text { (days) }\end{array}$} & \multirow{2}{*}{$\begin{array}{l}\operatorname{Re} \\
\left(\Omega . \mathrm{cm}^{2}\right)\end{array}$} & \multirow{2}{*}{$\begin{array}{l}R_{p} \\
\left(\mathrm{k} \Omega \cdot \mathrm{cm}^{2}\right)\end{array}$} & \multicolumn{2}{|l|}{$Q$} & \multirow{2}{*}{$\frac{C_{e f f}{ }^{*}}{u F / \mathrm{cm}^{2}}$} \\
\hline & & & & $Y_{o}\left(\mu \Omega \cdot \mathrm{cm}^{-2} \mathrm{~s}^{-\alpha 1}\right)$ & $\alpha$ & \\
\hline \multirow{8}{*}{ OPC } & $1 / 2$ & 10 & 372 & 50 & 0.94 & 30.7 \\
\hline & 1 & 10 & 614 & 47 & 0.94 & 28.8 \\
\hline & 2 & 10 & 938 & 44 & 0.94 & 26.8 \\
\hline & 3 & 10 & 1274 & 43 & 0.94 & 26.2 \\
\hline & 4 & 10 & 1505 & 42 & 0.94 & 25.6 \\
\hline & 5 & 10 & 1786 & 41 & 0.94 & 24.9 \\
\hline & 6 & 10 & 1941 & 41 & 0.94 & 24.9 \\
\hline & 7 & 10 & 2018 & 41 & 0.94 & 24.9 \\
\hline \multirow{8}{*}{ BYF } & $1 / 2$ & 19 & 465 & 45 & 1.00 & 45.0 \\
\hline & 1 & 19 & 680 & 44 & 0.95 & 30.3 \\
\hline & 2 & 19 & 926 & 43 & 0.95 & 29.6 \\
\hline & 3 & 19 & 1018 & 42 & 0.95 & 28.8 \\
\hline & 4 & 20 & 1093 & 42 & 0.95 & 28.8 \\
\hline & 5 & 20 & 1137 & 41 & 0.95 & 28.2 \\
\hline & 6 & 20 & 1184 & 41 & 0.95 & 28.2 \\
\hline & 7 & 20 & 1222 & 41 & 0.95 & 28.2 \\
\hline
\end{tabular}

* Effective capacitance calculated using Eq. 2. 
Table 5 Calculated layers thickness from XPS results.

\begin{tabular}{ccc} 
Solution & Immersion (days) & $\boldsymbol{D}(\mathbf{n m})$ \\
\hline OPC & 1 & 5.1 \\
\cline { 3 - 4 } BYF & 1 & 4.9 \\
OPC & 2 & 4.6 \\
BYF & 2 & 4.7 \\
\hline
\end{tabular}




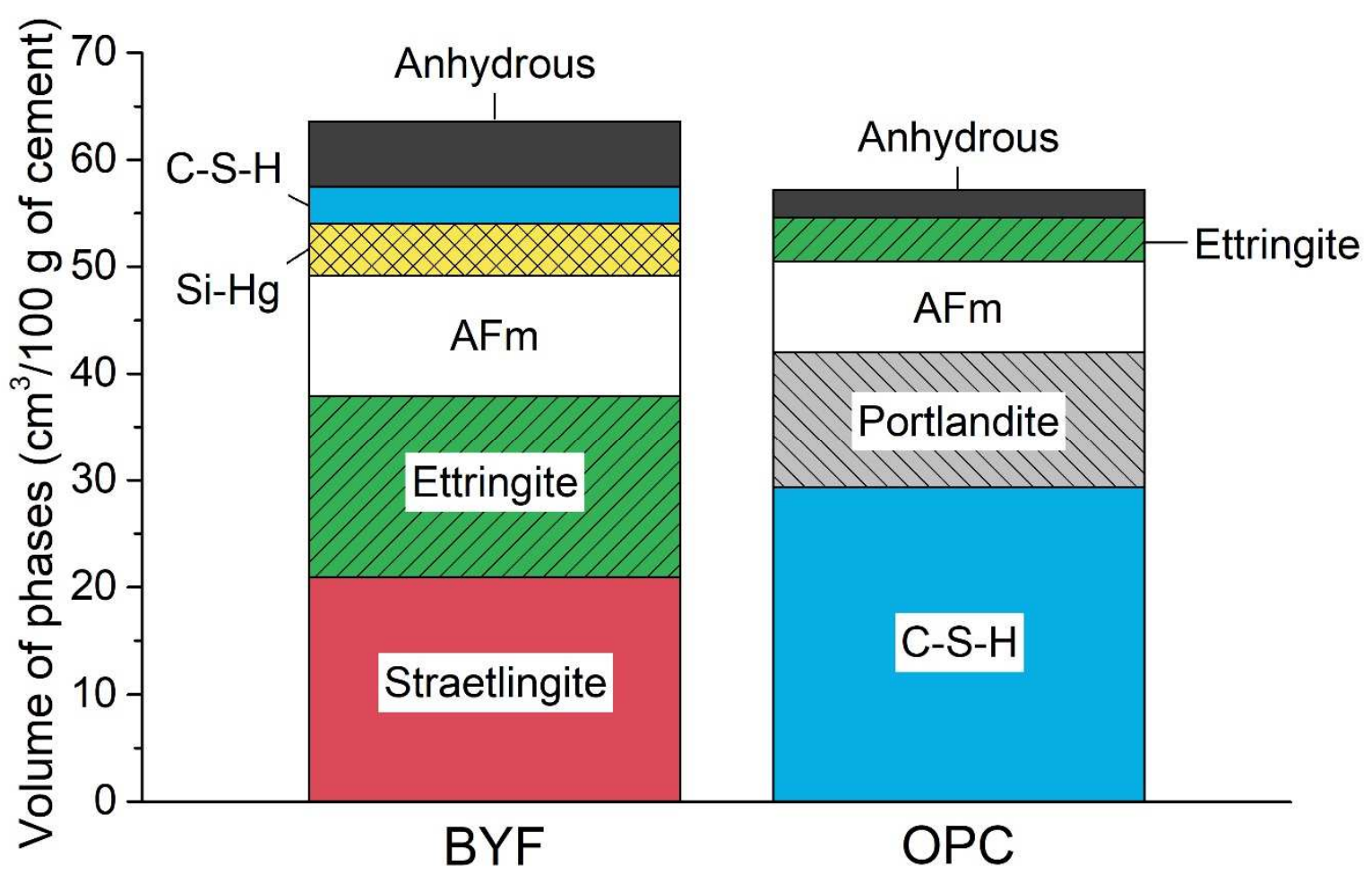

Fig. 1 Main phases at 28 days of hydration of OPC and BYF cement pastes with water-tocement ratio of 0.50 . The phases were estimated by Rietveld refinement as in [13]. AFm is shorthand for a family of hydrated calcium aluminate phases structurally related to hydrocalumite and occurring mainly in hydrated cement paste. Si-Hg and C-S-H stand for siliceous hydrogarnet and calcium-silicate hydrate, respectively. 
a)

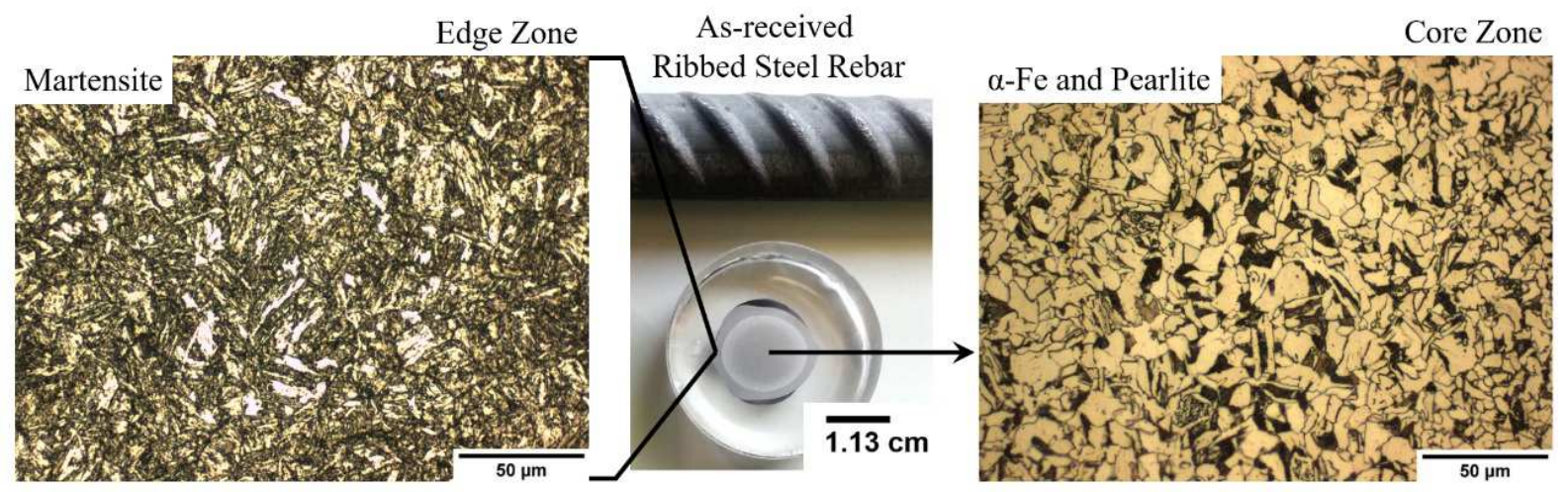

b)

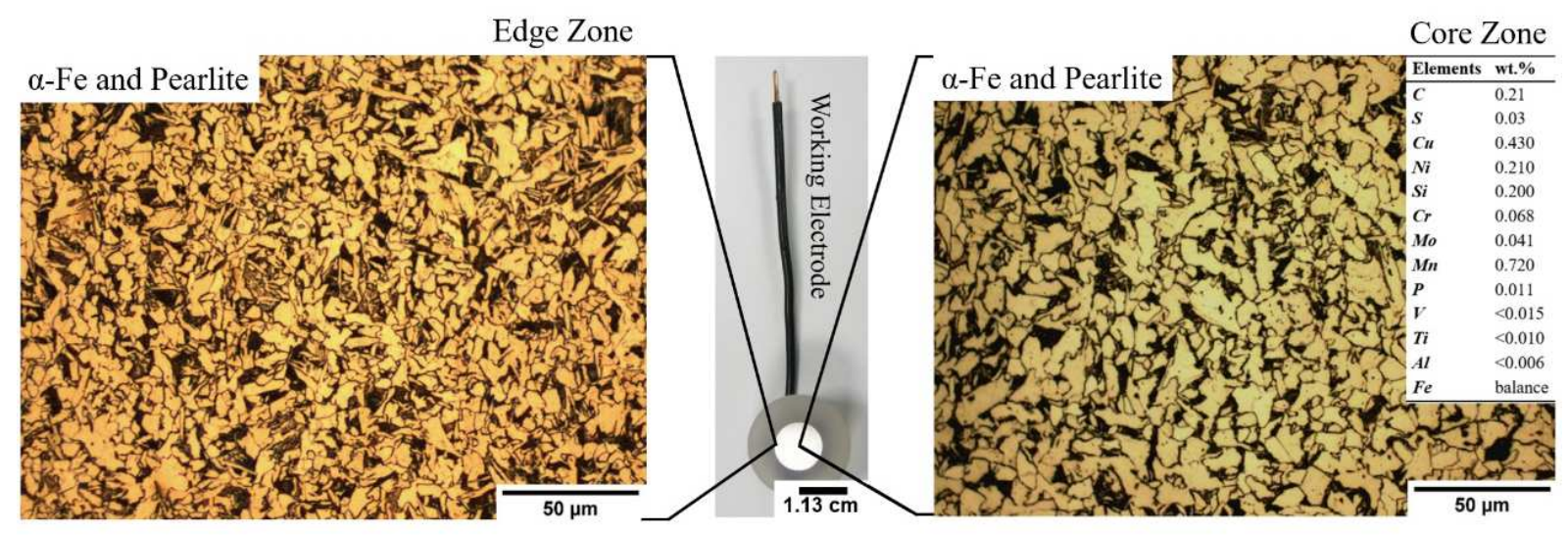

Fig. 2 Cross-sectional optical micrographs (500x, after Nital 2\% etching) taken at a) the edge (martensite) and the core ( $\alpha$-Fe and pearlite) of the as-received ribbed steel rebar, and $b$ ) taken at the edge and core of the steel after rib removal, showing in both cases a ferrite plus pearlite microstructure with a slight different in grain refinement. Carbon and sulfur content determined by high-frequency and infrared detection. Other elements determined by spark optical emission spectrometry. Central image: assembled working-electrode. 


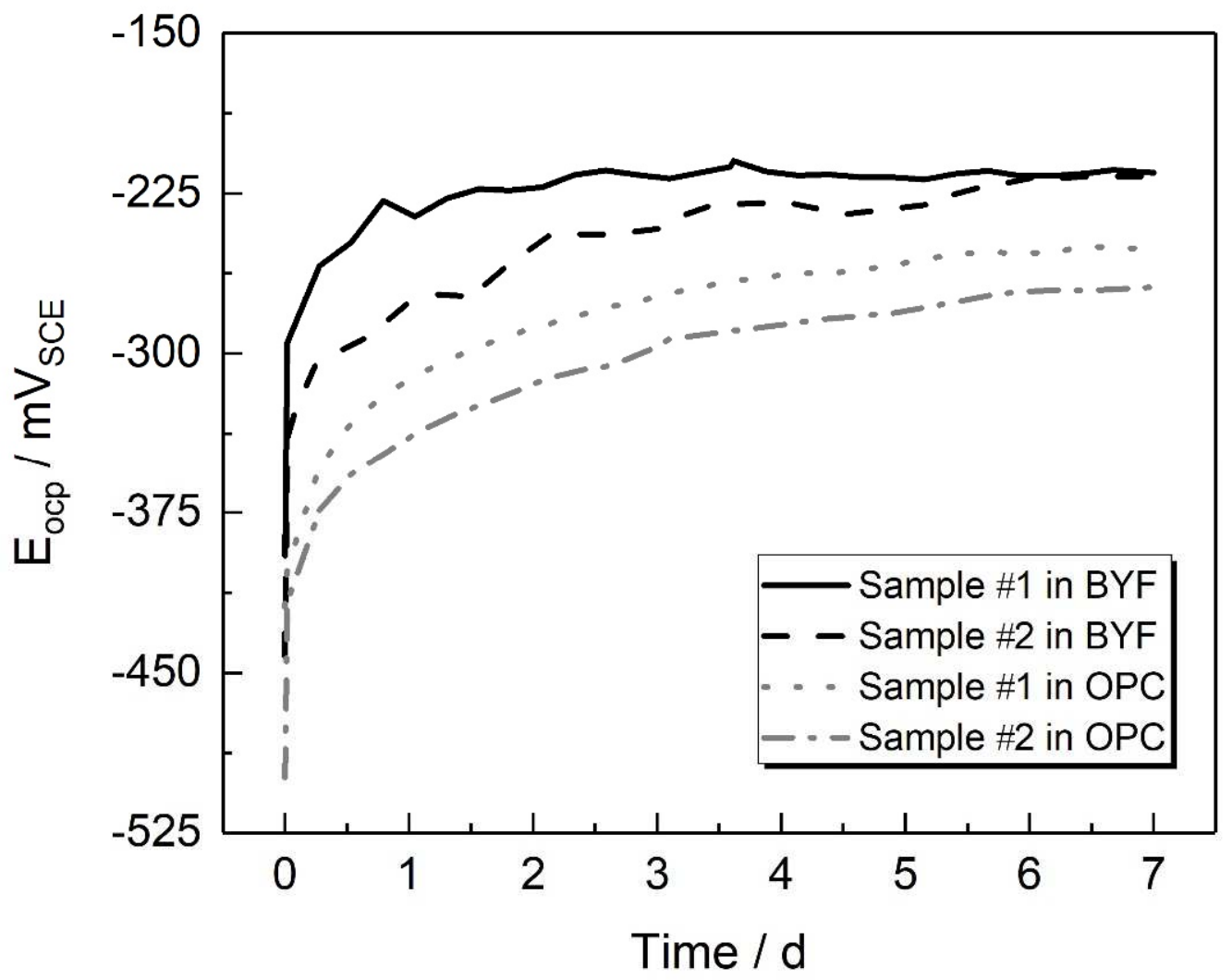

Fig. 3 Increase of the $E_{\text {ocp }}$ values with time of steel immersed in OPC and BYF solutions. Numbers \#1 and \#2 stand for two different samples analyzed in the same condition to verify the repeatability. 
a)

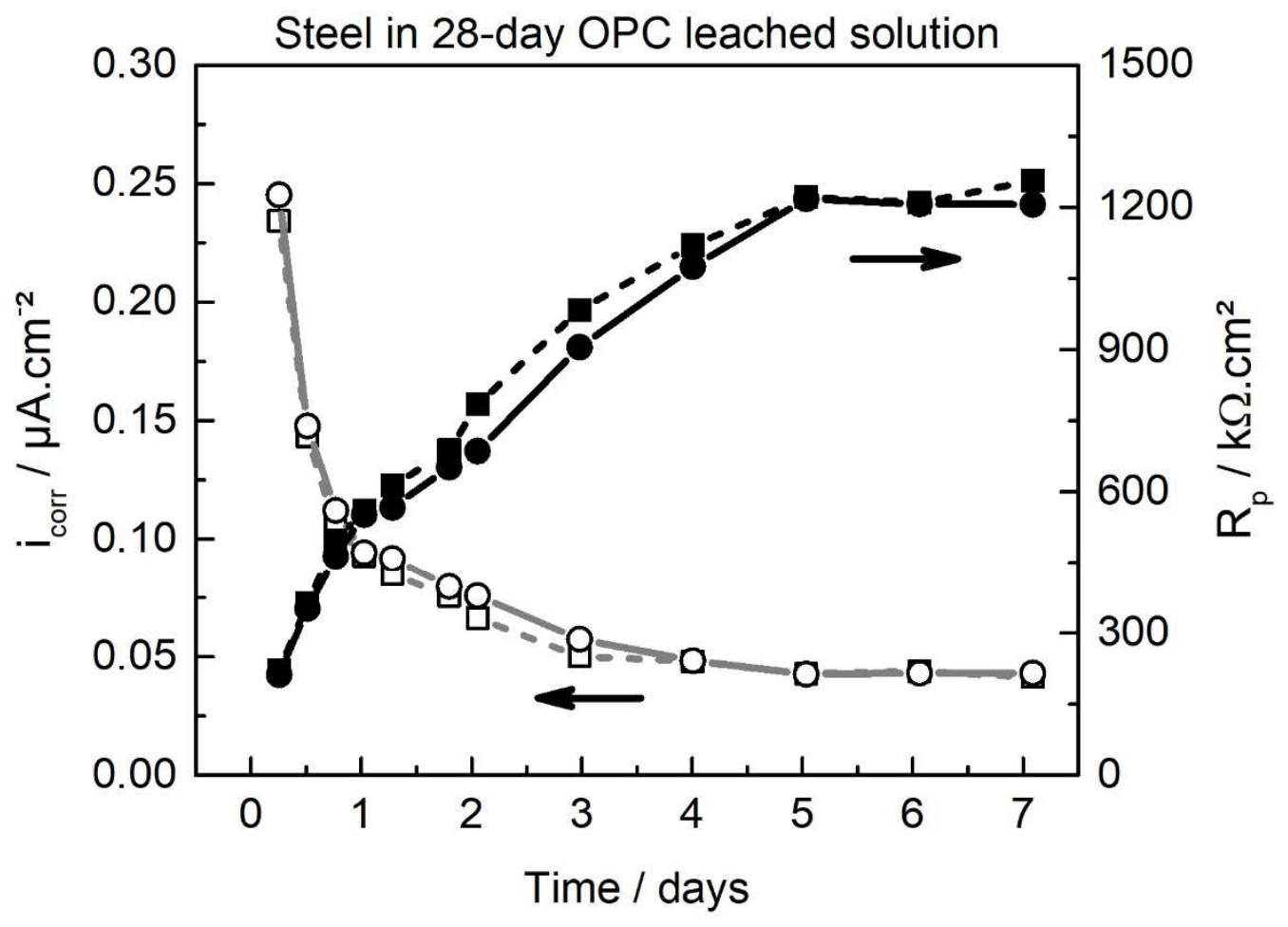

b)

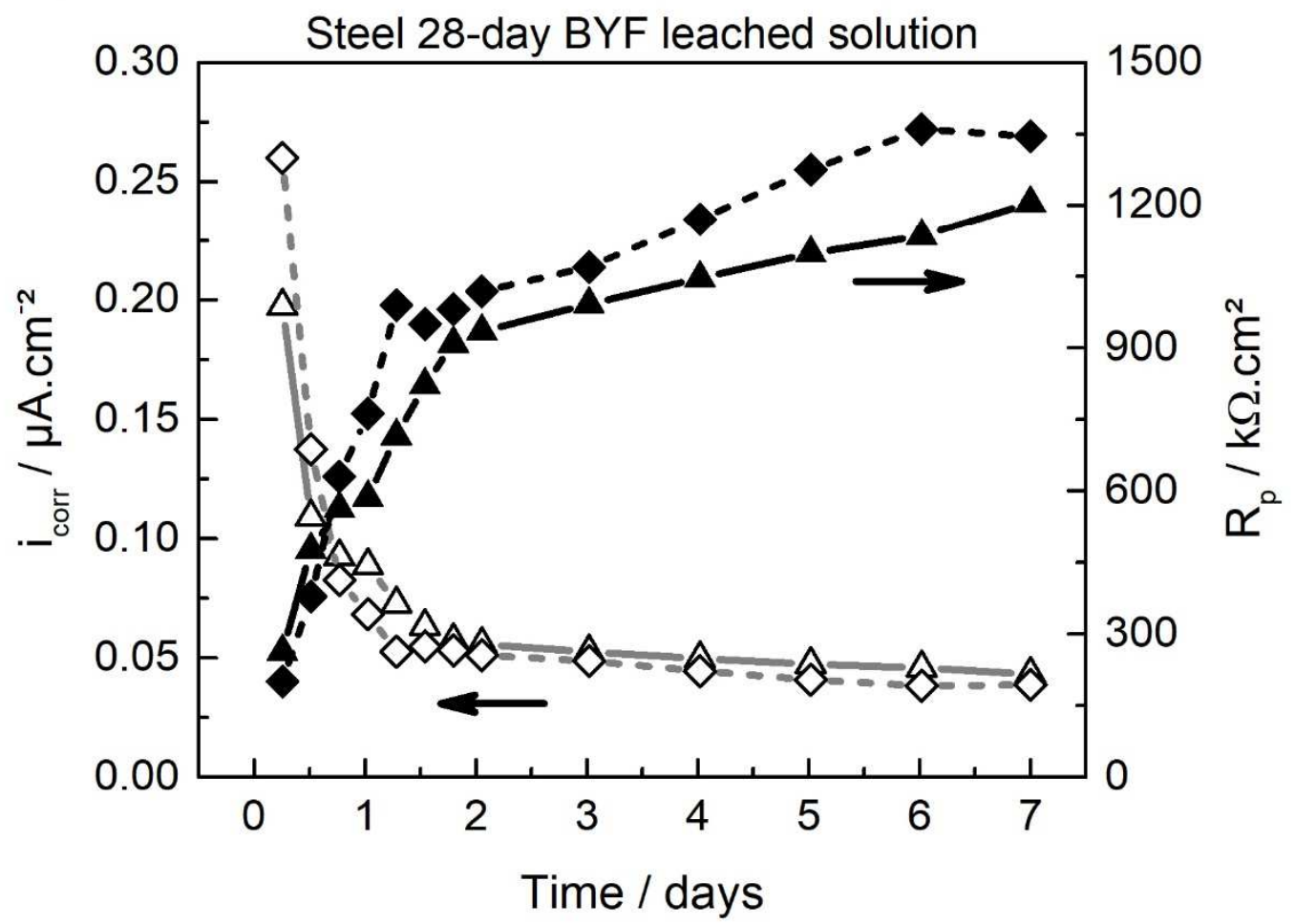

Fig. 4 Corrosion resistance evolution in terms of $R_{p}$ (solid dots) and the corresponding $i_{\text {corr }}$ (open dots) values for a) two steel samples immersed in OPC solution, and b) two steel samples in BYF solution. The $i_{\text {corr }}$ are calculated from the Stern-Geary equation, assuming $B$ $=52 \mathrm{mV}$. 
a)

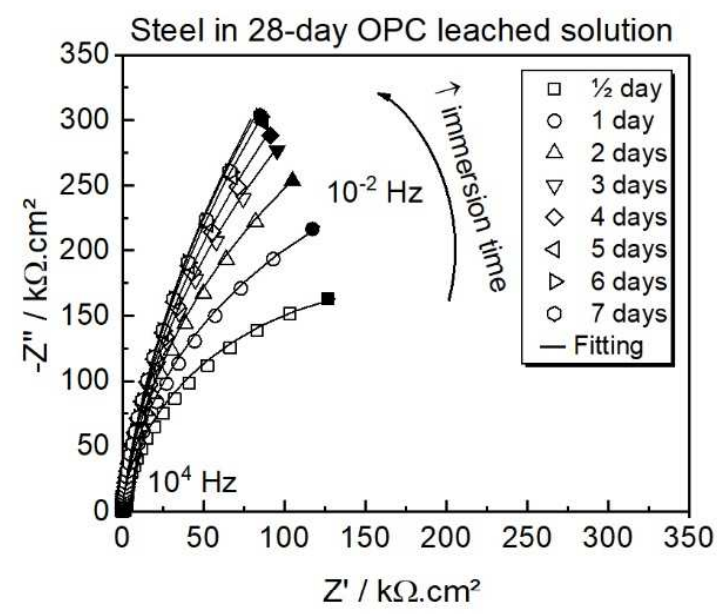

c)

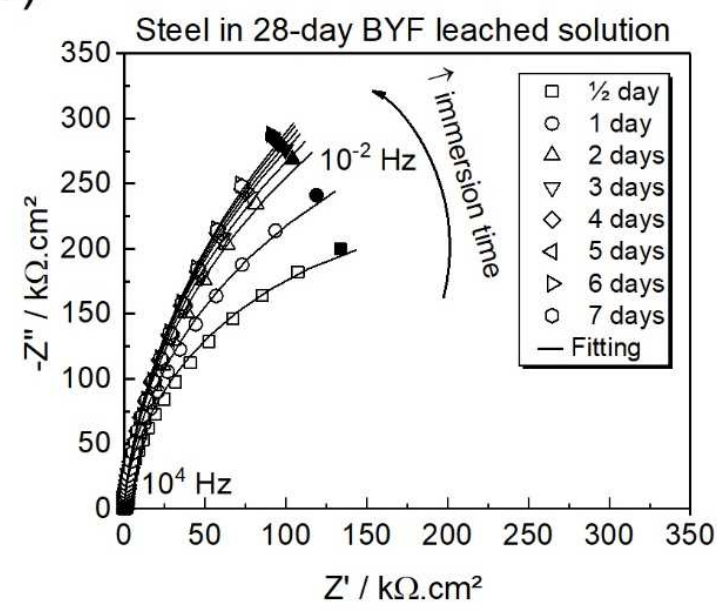

b)

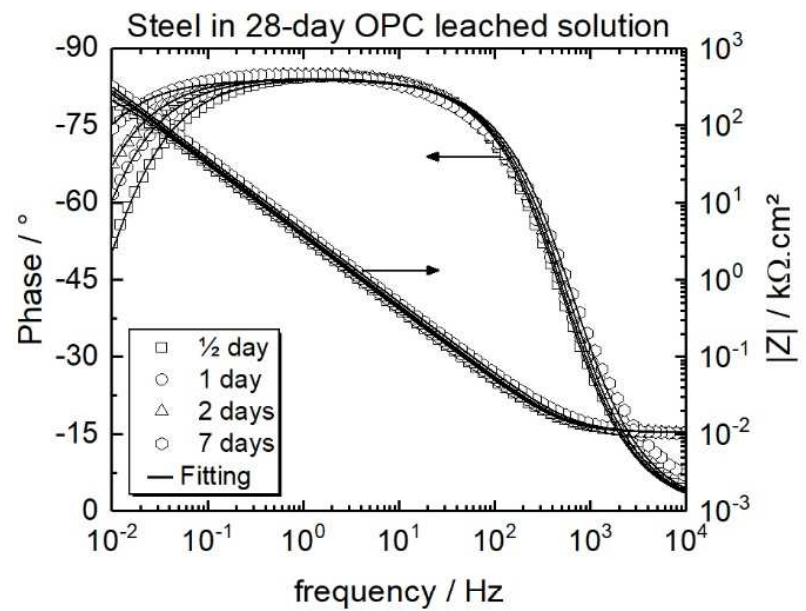

d)

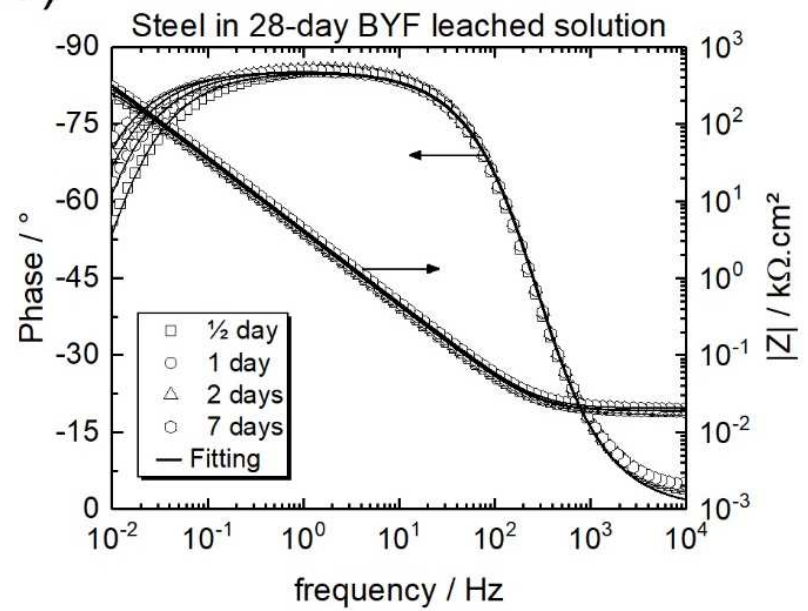

Fig. 5 Nyquist plots for steel immersed in a) OPC solution, and c) BYF solution. Bode plots for steel immersed in b) OPC solution, and d) BYF solution. The Bode plots for 3, 4, 5, and 6 days are not included to better visualize the trends. 


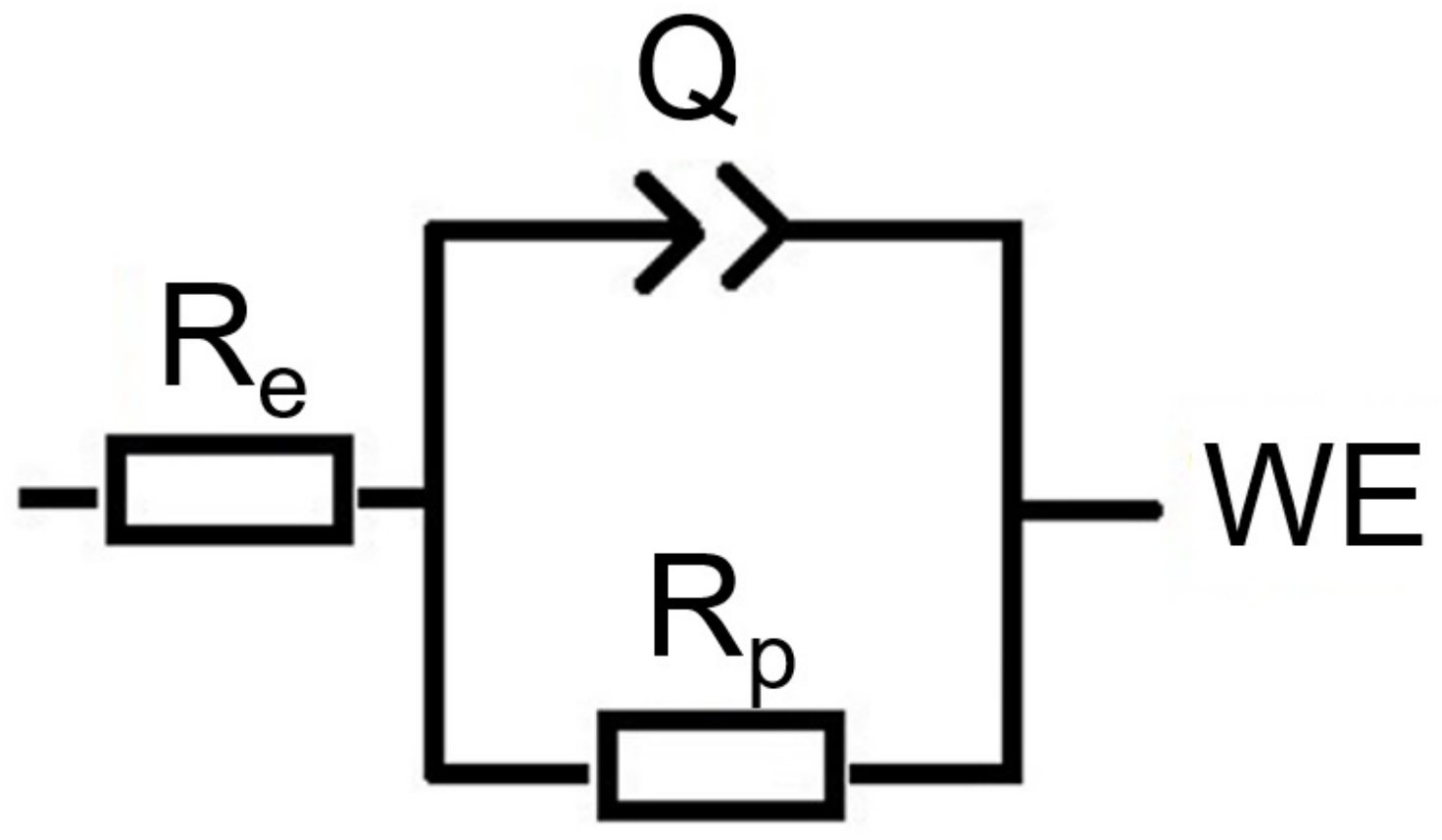

Fig. 6 Equivalent circuit with one-time constant in series with a resistor (referred to as modified Randle's circuit). 
a)

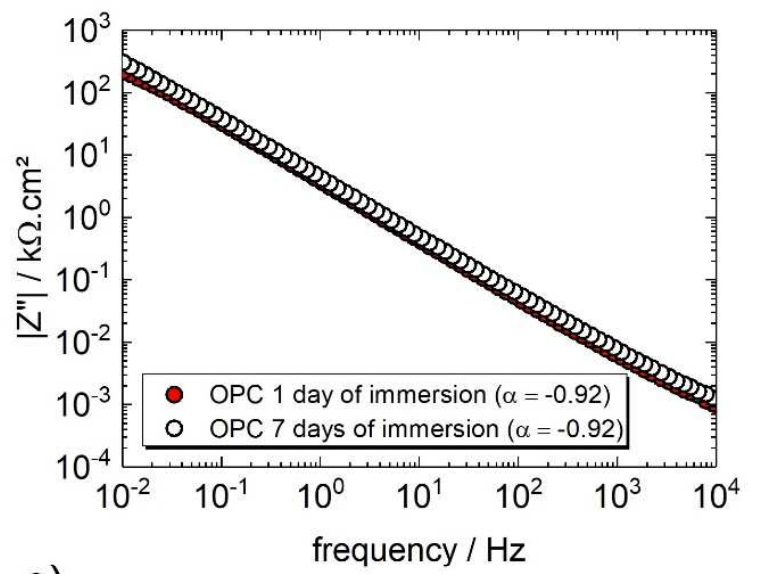

c)

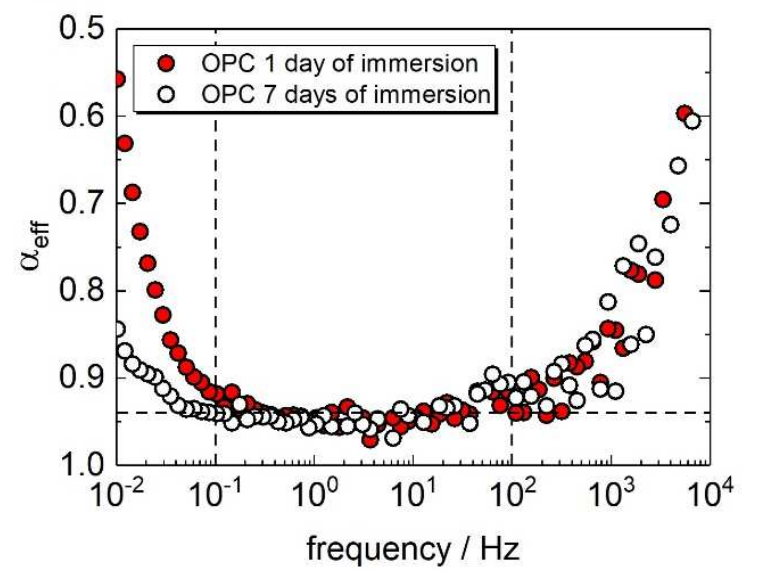

b)

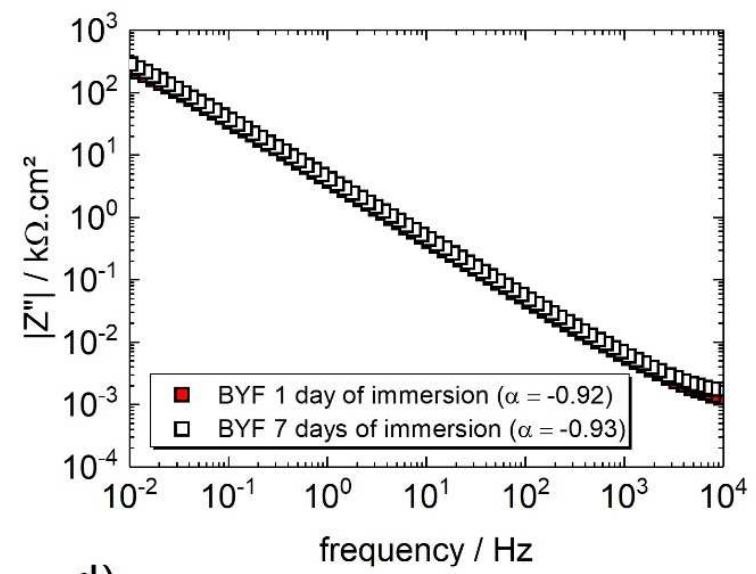

d)

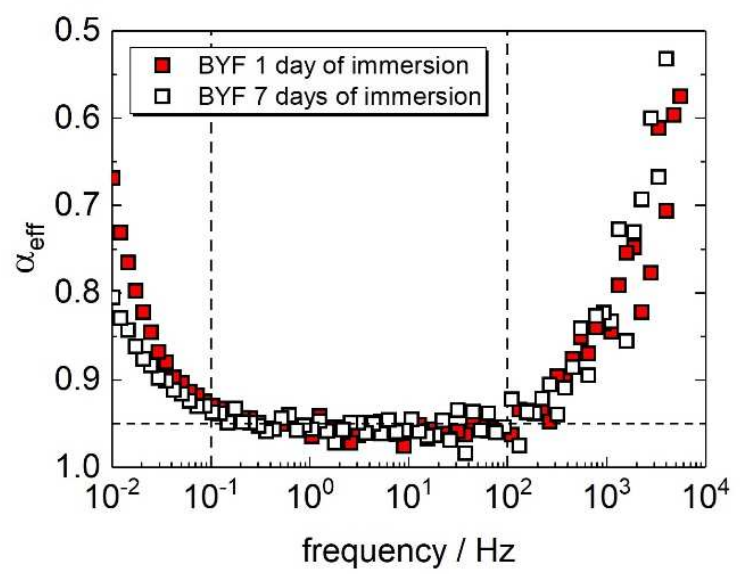

Fig. 7 Imaginary part of the impedance as a function of the frequency of a) steel in OPC extract and b) steel immersed in BYF extract. Constant phase element behavior between 1 and 7 days of c) steel immersed in OPC extract, and d) steel immersed in BYF extract. Horizontal dashed lines represent the saturation mean values considered for $\alpha_{\text {eff. }}$. 
a)

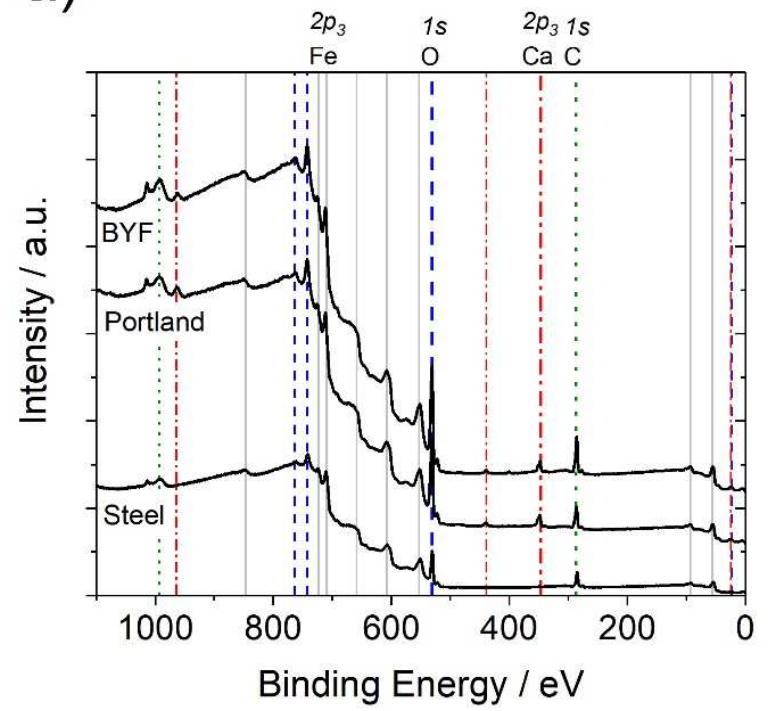

b)

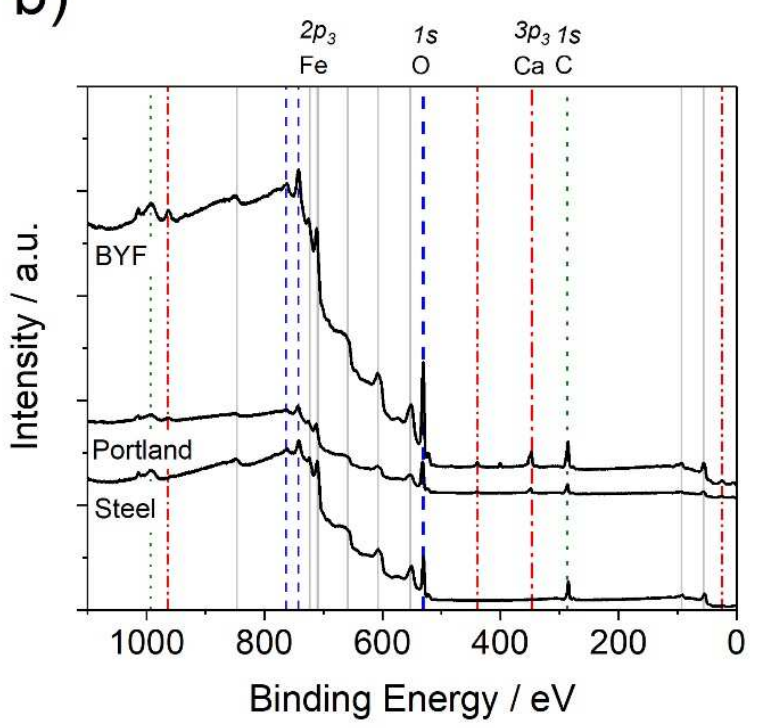

Fig. 8 Survey XPS spectra at $90^{\circ}$ of steel embedded in OPC and BYF extracts during a) 1 day, and b) 2 days. The spectra of steel exposed to air during $5 \mathrm{~min}$ is also shown. 
a)

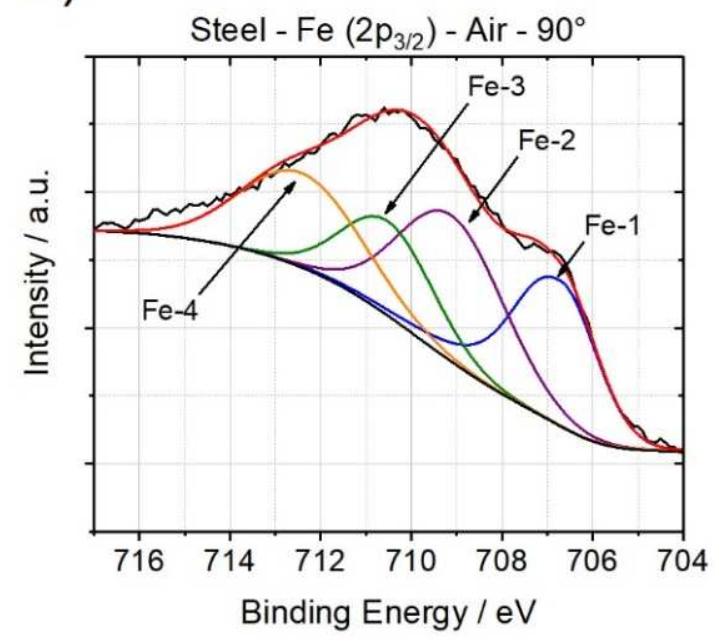

c)

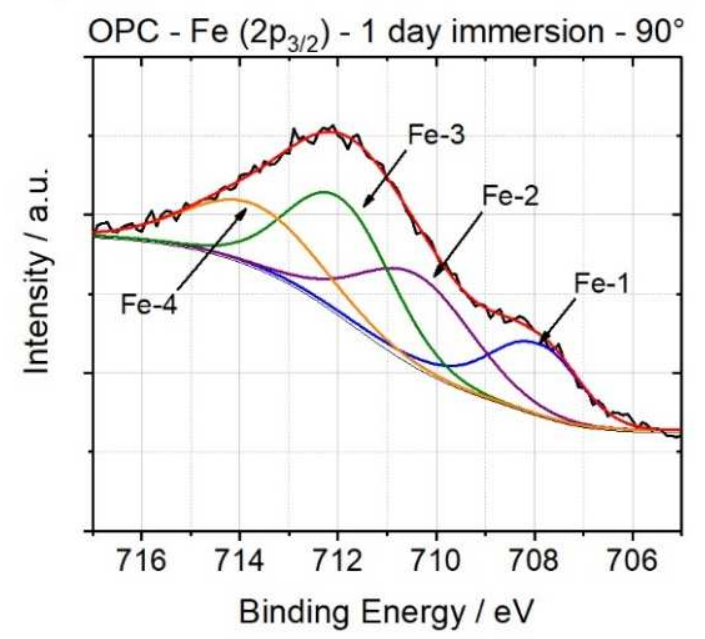

e)

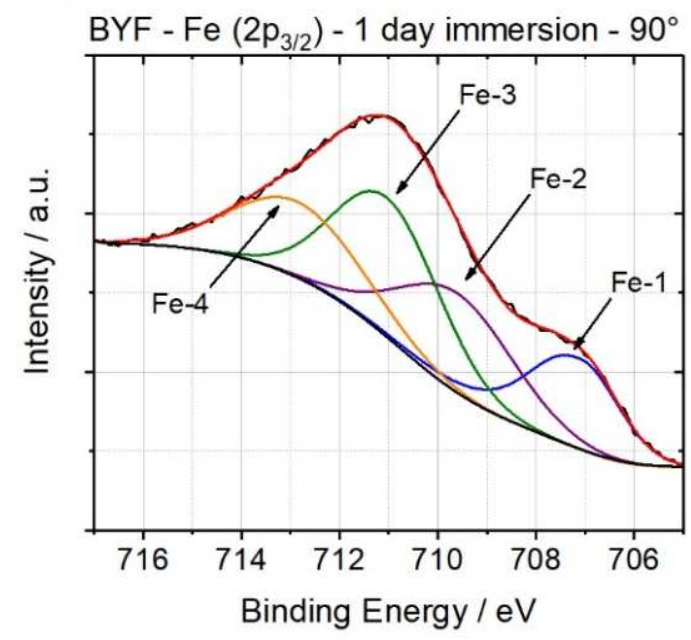

b)

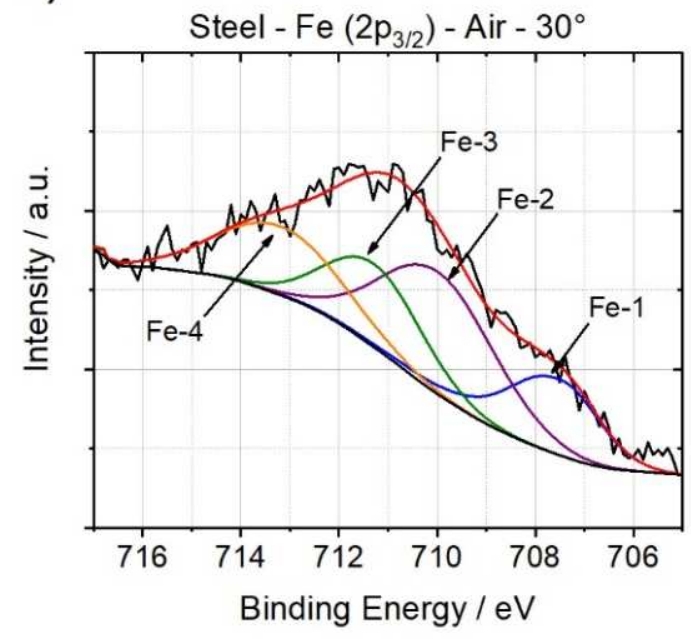

d)

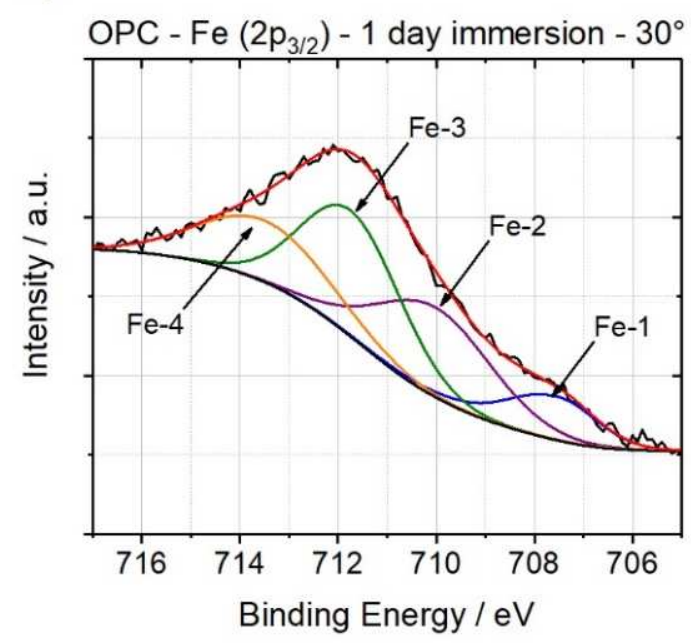

f)

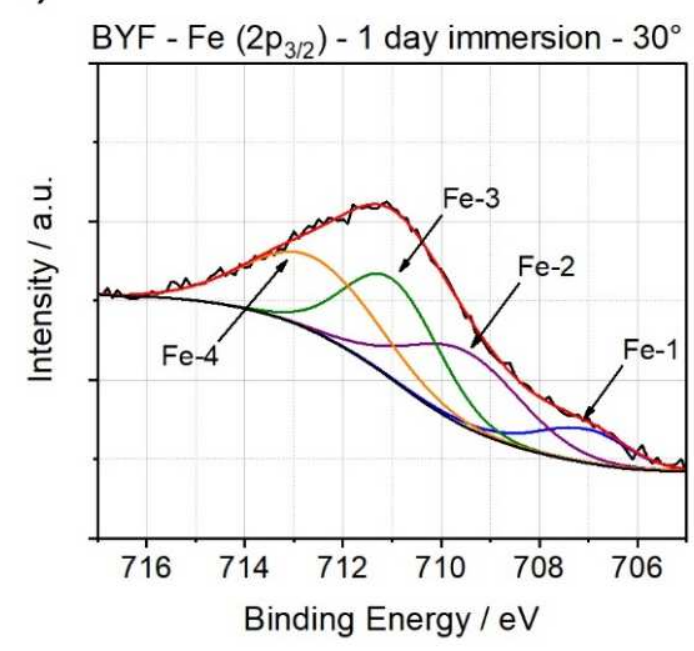

Fig 9 Specific Fe $2 p$ XPS spectra and their decompositions for a) and b) steel exposed to air for 5 min., c) and d) steel immersed for 1 day in OPC solution, and e) and f) steel immersed in BYF solution for 1 day. 
a)

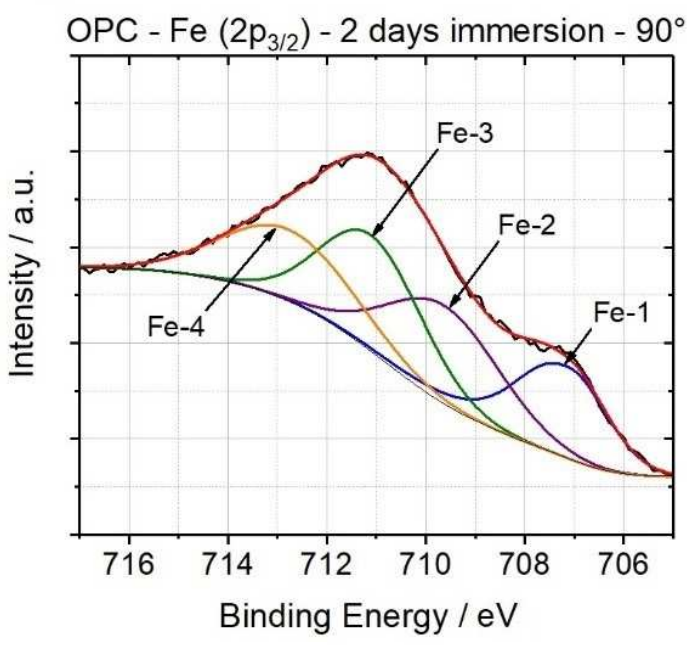

c)

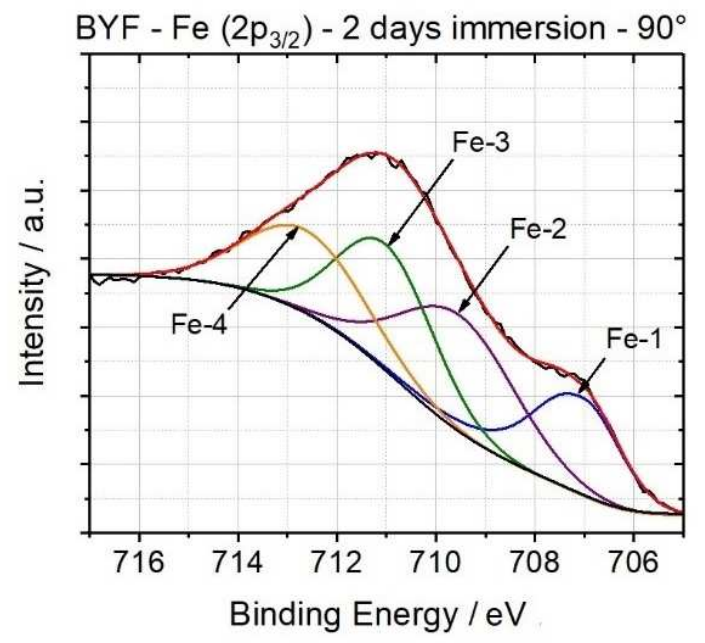

b)

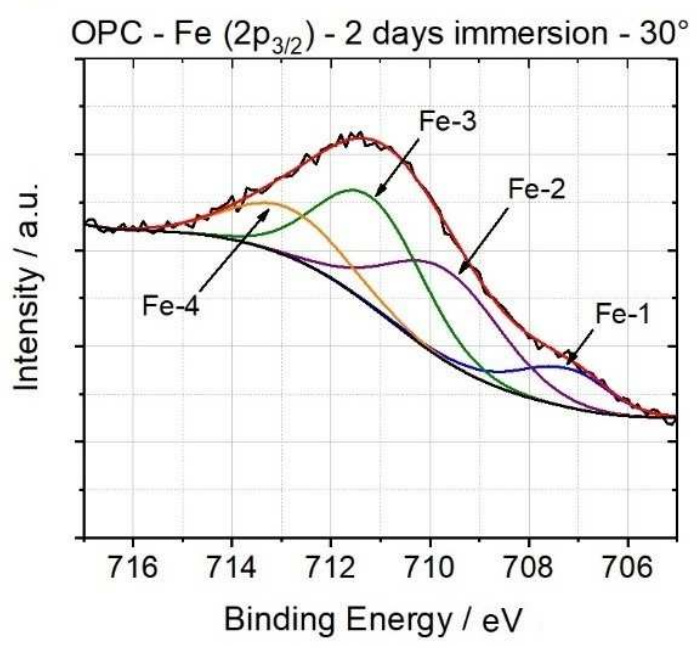

d)

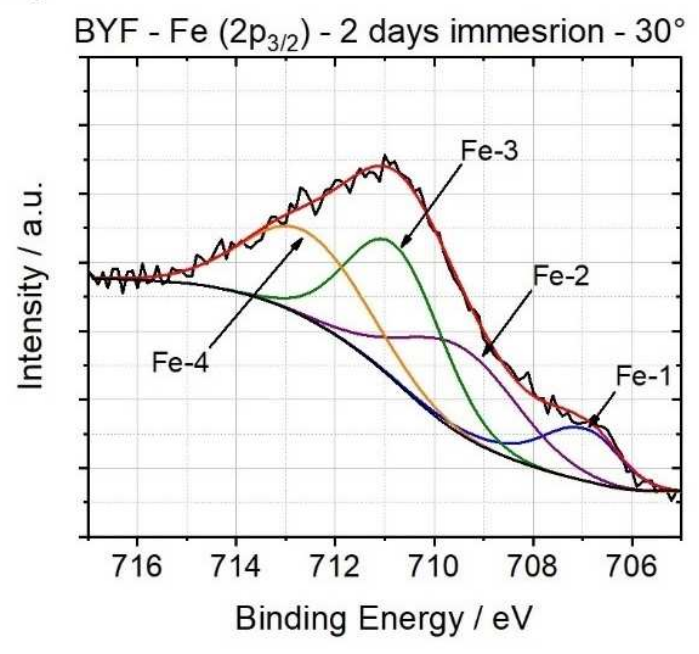

Fig. 10 Specific Fe2p XPS spectra and their decompositions for a) and b) steel immersed in OPC solution for 2 days, c) and d) steel immersed in BYF solution for 2 days. 


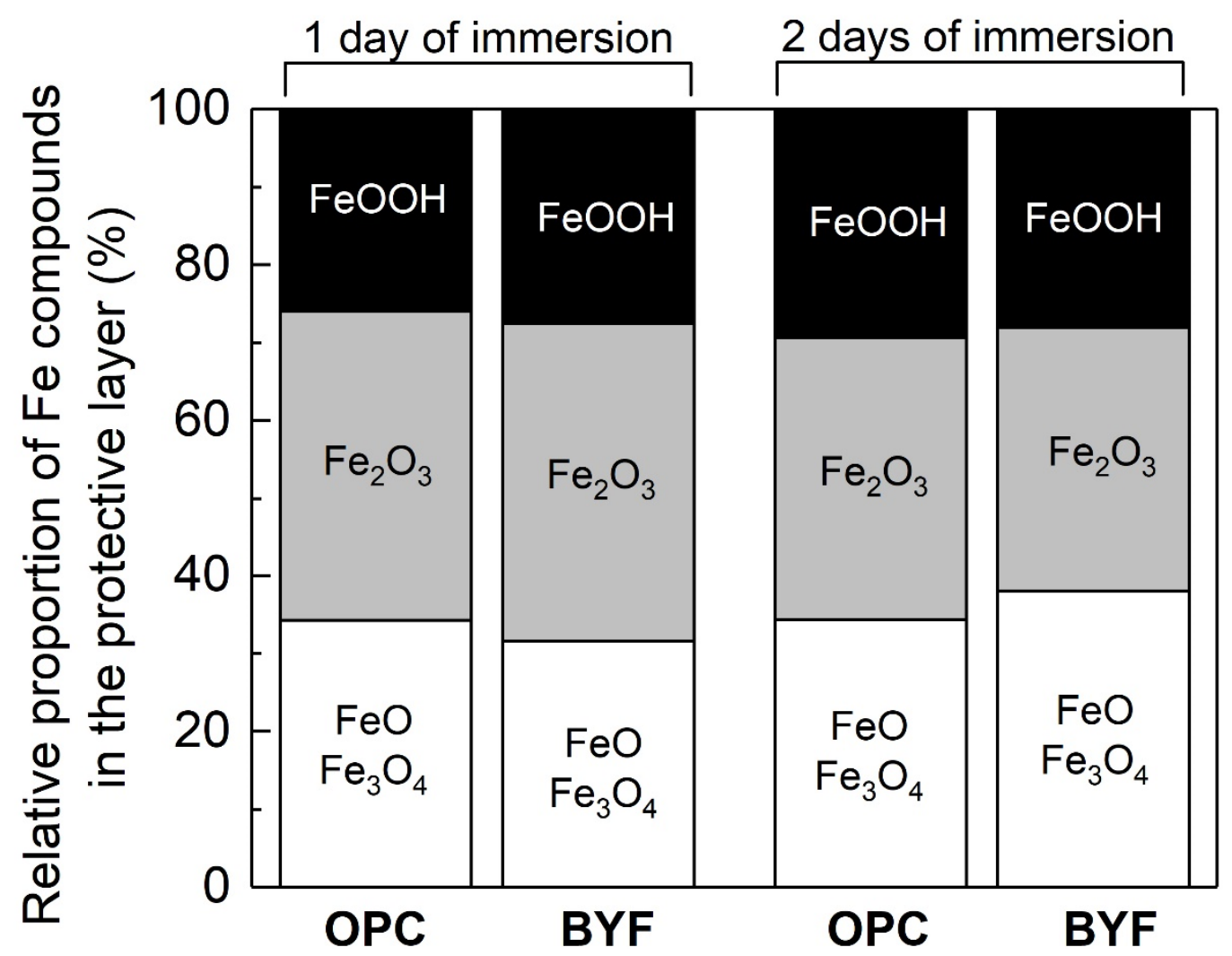

Fig. 11 Similarity of the relative proportions of iron compounds considering the XPS specific $\mathrm{Fe} 2 p$ spectra at $90^{\circ}$ of steel immersed in OPC and BYF electrolyte. 
